\title{
$N$-烷基胺类作为多功能砌块在氧化偶联反应中的应用
}

\author{
陈缘夏立静常怡婷 马武珍王 涁* \\ (南开大学药学院 天津 300353)
}

\begin{abstract}
摘要 $N$-烷基胺的氧化官能团化是形成碳-碳键和碳-杂原子键的最直接和通用的策略之一. 近年来, $N$-烷基胺类作为 多功能砌块在交叉脱氢偶联(CDC)反应中取得了长足发展. 基于 $N$-烷基胺的不同角色，总结了近年来它们在氧化偶联 反应中的应用进展.

关键词 $N$-烷基胺; $N, N$-二甲基苯胺; 四氢异喹啉; 交叉脱氢偶联反应
\end{abstract}

\section{Application of N-Alkyl Amines as Versatile Building Blocks in Oxidative Coupling Reactions}

\author{
Chen, Yuan Xia, Lijing Chang, Yiting Ma, Wuzhen Wang, Bin* \\ (College of Pharmacy, Nankai University, Tianjin 300353)
}

\begin{abstract}
The oxidative functionalization of $N$-alkylamines is one of the most direct and versatile strategies for the formation of $\mathrm{C}-\mathrm{C}$ and $\mathrm{C}$-heteroatom bonds. In recent years, $N$-alkylamines as multifunctional blocks have made great progress in crossdehydrogenation-coupling (CDC) reactions. The recent progress in the application of $N$-alkylamines is summarized on the basis of different roles in oxidative coupling reactions.

Keywords $N$-alkylamines; $N, N$-dimethylamine; tetrahydroisoquinoline; cross-dehydrogenative-coupling reaction
\end{abstract}

$\mathrm{N}$-Alkylamines are readily available reagents and widely used in organic synthesis. Recently, $\mathrm{C}-\mathrm{H}$ bond functionalization reactions have been intensively studied due to their step- and atom-economy. Among these $\mathrm{C}-\mathrm{H}$ bond transformations, the oxidative cross-dehydrogenative coupling (CDC) reactions have attracted considerable attentions. ${ }^{[1]}$ These reactions were used to form carbon-carbon $(\mathrm{C}-\mathrm{C})$ or carbon-heteroatom $(\mathrm{C}-\mathrm{X})$ bonds from two $\mathrm{C}-$ $\mathrm{H}$ bonds or a $\mathrm{C}-\mathrm{H}$ bond with a heteroatom- $\mathrm{H}$ bond. As the $\mathrm{C}-\mathrm{H}$ bond adjacent to nitrogen atom is readily activated under oxidative conditions, many $N$-alkylamines are suitable coupling partners in CDC reactions and they provide a convenient nitrogen and/or carbon sources for the synthesis of the desired products. They can serve as alkylation, acylation agents as well as $\mathrm{N}$ or $\mathrm{C}$ donors. Although several excellent reviews involving the oxidative coupling reactions of $\mathrm{N}$-alkylamines have been published from different perspectives, ${ }^{[2]}$ there are no summaries aiming at the roles of $N$-alkylamines in the published works. In 2018, Edwards and coworkers ${ }^{[3]}$ reviewed various selection of catalysts and various selectively substituted amines that can be accessed by hydroaminoalkylation, which is forming $\mathrm{C}-\mathrm{C}$ bonds through $\mathrm{C}-\mathrm{H}$ bond activation via $\alpha$-position of amines and subsequent reaction with an alkene or alkyne. Thus, these hydroaminoalkylations of alkenes or alkynes with amines were omitted in this review. Transition-metal-catalyzed $\mathrm{C}-\mathrm{N}$ bond cleavage of amines has been well summarized by Xi's group. ${ }^{[4]}$ In this review, only some representative examples of deamination of $\mathrm{N}$-alkylamines will be summarized. The content is organized according to the order of amines with aim to provide a current, comprehensive and organized overview of the application of $\mathrm{N}$-alkylamines in oxidative coupling reactions. Among these amines, the reactions of $N, N$-dimethyl amines and tetrahydroisoquinolines (THIQs) are much more than that of secondary and primary amines. Some useful mechanisms are presented based on the reactions of $N, N$-dimethyl amines and THIQs. We believe that the CDC reaction of $N$-alkyl amines is just the tip of the iceberg and numerous novel reactions of $N$-alkyl amines are

\footnotetext{
* Corresponding author. E-mail: wangbin@nankai.edu.cn

Received September 14, 2020; revised October 27, 2020; published online December 3, 2020.

Project supported by the Tianjin Municipal Science and Technology Commission (No. 19JCTPJC48400) and the National University Student Innovation Program (No. 201910055456).

天津市科学技术委员会(No. 19JCTPJC48400)和国家大学生创新(No. 201910055456)资助项目.
} 
going to be disclosed in the future.

\section{Reactions of tertiary amines}

The oxidative coupling reactions of $N, N$-dialkylanilines and tetrahydroisoquinolines (THIQs) are reviewed in this section. Chemists have made many efforts in $\mathrm{C}-\mathrm{C}$ or C-heteroatom coupling reactions at the $\mathrm{C}(1)$ position of THIQs or $\alpha$-C of $N, N$-dialkylanilines.

\subsection{Alkylation reagents}

\subsubsection{Alkylation of alkanes}

In 2005, Li and coworkers ${ }^{[5]}$ disclosed a seminal CDC reaction of tertiary amines with nitroalkanes under the copper-catalyzed conditions. The coupling partners nitroalkanes also served as solvents in these transformations (Scheme 1). The authors speculated three types of intermediates $\mathbf{1} \sim \mathbf{3}$ were most likely formed in the reaction. They were further converted into the corresponding cross-coupling products by the nucleophilic attack of nitroalkanes.

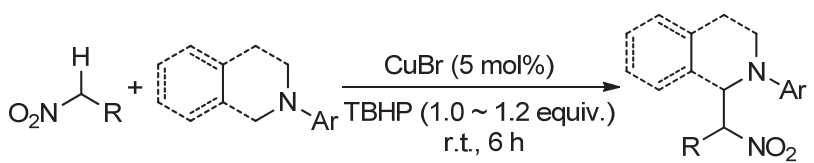

$\mathrm{R}=\mathrm{H}, \mathrm{Me}$ r.t., $6 \mathrm{~h}$ $30 \% \sim 92 \%$ yield

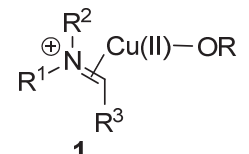<smiles>[R]C[N+]([O-])O[Ga]</smiles><smiles>[R]C(OCC)N([R])OCC</smiles>

Scheme 1 Copper-catalyzed CDC reaction of TIHQs and nitroalkanes

Nitroalkanes were frequently used as reaction partners due to their reactivity. In 2009, Todd's group ${ }^{[6]}$ developed a catalyst-free coupling reaction of THIQs with nitromethane by the use of 2,3-dichloro-5,6-dicyano-1,4-benzoquinone (DDQ). Based on their primary results, they proposed that an ion pair $\mathbf{4}$ from the iminium ion and phenolate was a key intermediate (Eq. 1).<smiles>[R]=Cc1ccc2c(c1)CCN([Al])C2</smiles>

$$
\mathrm{R}=\mathrm{H}, \mathrm{OMe}
$$

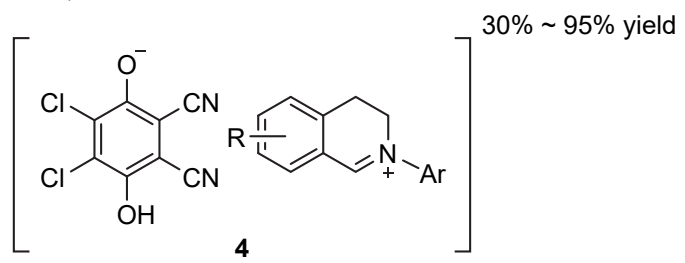

In the same year, a $\mathrm{PhI}(\mathrm{OAc})_{2}$-mediated $\mathrm{CDC}$ reaction of tertiary amines was developed by Liang's group. ${ }^{[7]}$ The method was applicable to the synthesis of diacetoxylated piperidines and coupling reactions of THIQs with nitroalkanes, dialkyl malonates and $\beta$-keto ester (Scheme 2). On the basis of the reported electrochemical and metalcatalyzed pathway, they proposed a similar hypervalent iodine mediated pathway. Iminium ion $\mathbf{5}$ was first formed through the oxidation of $\mathrm{PhI}(\mathrm{OAc})_{2}$. Enamine $\mathbf{6}$ was then formed via $\beta$-hydrogen elimination. The electrophilic addition of $\mathrm{PhI}(\mathrm{OAc})_{2}$ to the double bond to produce trans compound 7. Subsequent elimination of iodobenzene through $\mathrm{S}_{\mathrm{N}} 2$ pathway afforded cis-2,3-diacetoxylated product 8 .
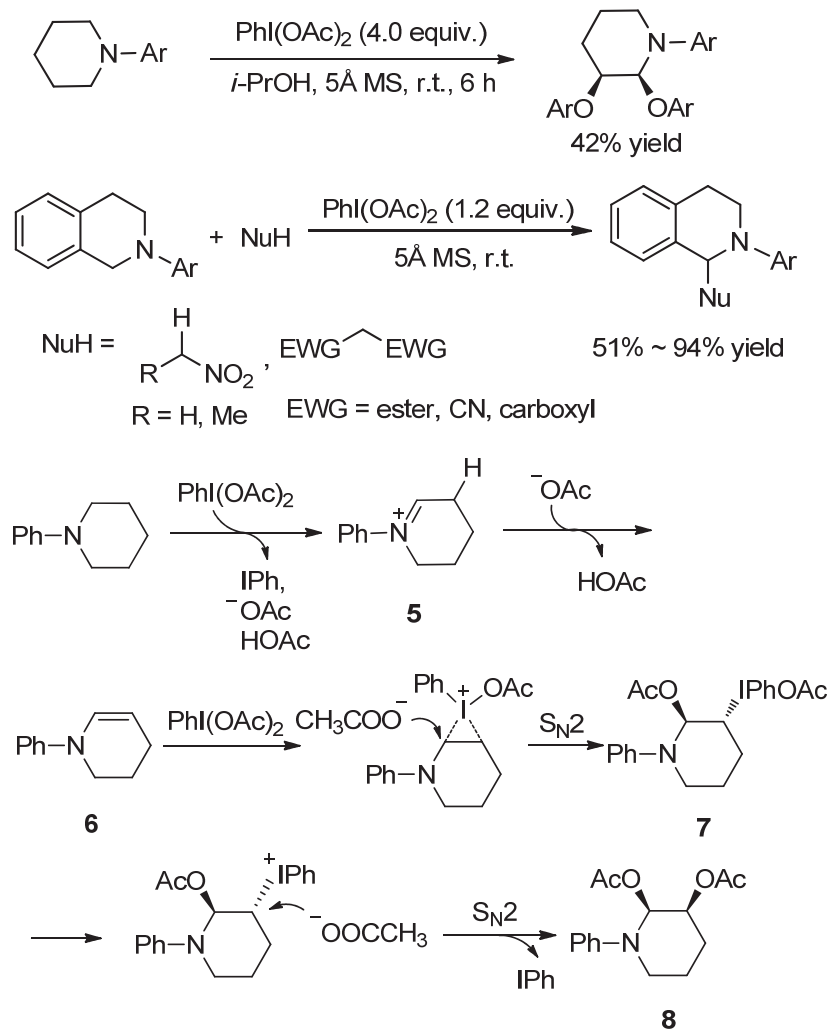

Scheme $2 \mathrm{PhI}(\mathrm{OAc})_{2}$-mediated $\mathrm{CDC}$ reaction of tertiary amines

In 2010, Qing and coworkers ${ }^{[8]}$ studied the metal-free CDC reaction of THIQs with (trifluoromethyl)trimethylsilane. They obtained various 1-triflfluoromethylated TIHQ derivatives under benzoyl peroxide (BPO)-promoted conditions. Besides the desired product 9, they also noted that an over oxidation occurred to produce product $\mathbf{1 0}$, which can be easily converted to the desired product 9 with hydrogenation (Scheme 3 ). They assumed that the reaction proceeded through a radical intermediate 11, which was probably generated by hydrogen transfer via either of two different pathways. Then iminium intermediate 12 was formed from 11 via electron transfer. Finally, the nucleophilic reaction of $\mathrm{CF}_{3}{ }^{-}$with $\mathbf{1 2}$ gave the product $\mathbf{9}$.

After Li's seminal works, various oxidative coupling reactions of THIQs have been reported. However, the mechanism of this type reaction was unclear until 2012. Although chemists generally considered that the iminium ion was a key intermediate in these reactions, the detailed reaction pathways were different due to the various reaction system. 


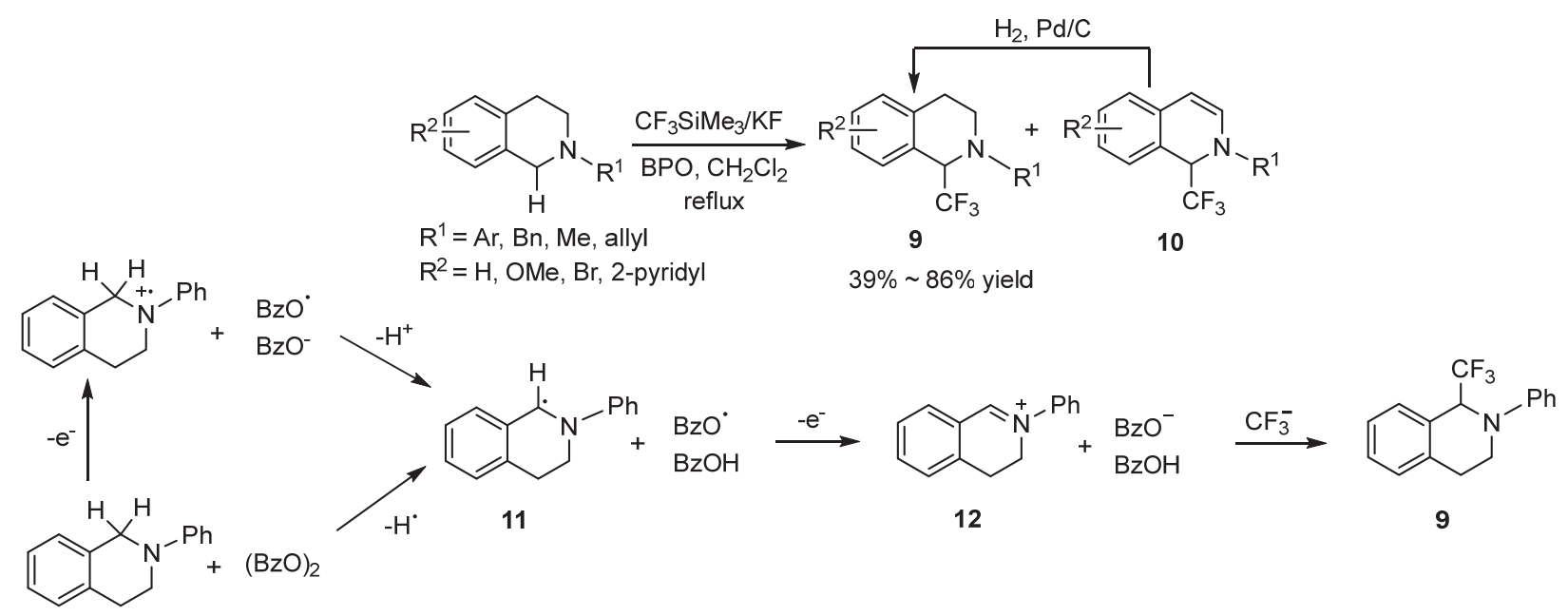

Scheme 3 Trifluoromethylation of TIHQs

In 2011, Klussmann's group ${ }^{[9]}$ performed some control experiments to investigate the mechanism for these CDC reactions of THIQs. During the aerobic copper-catalyzed oxidative coupling reaction of $N$-phenyl THIQs with silyl enolate in methanol, iminium dichlorocuprate $\mathbf{1 3}$ was trapped and further confirmed by X-ray diffraction. It was regarded as the reactive intermediate in the catalytic cycle. As shown in Scheme 4, oxidation of THIQ resulted in the formation of reactive iminium cuprate species 13, which then reacted with methanol or water in an off-cycle equilibrium. The authors proposed that the resulting intermediates $\mathbf{1 4}$ and $\mathbf{1 5}$ acted as sources of the reactive iminium ion of $\mathbf{1 3}$. The weakly nucleophilic silyl enol ether $\mathbf{1 6}$ reacted with 13 to form the final product $\mathbf{1 7}$. The copper catalyst was stimuously regenerated by reoxidation with oxygen (Scheme 4).

In 2012, Klussmann and coworkers ${ }^{[10]}$ further investigated the CDC reaction of various $N$-alkyl THIQs with a broad range of nucleophiles, including nitroalkanes, ketones, heteroarenes and terminal alkynes. The combination of $\mathrm{VO}(\mathrm{acac})_{2} / m$-CPBA was employed in the catalystic

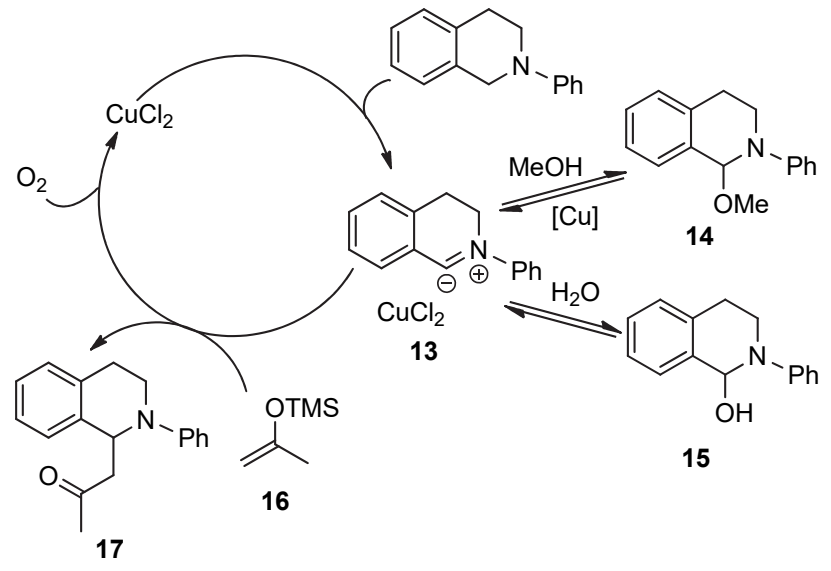

Scheme 4 Mechanism for the Cu-catalyzed reaction of THIQs

transformation. They proposed a Cope elimination type mechanism, and amine oxide $\mathbf{1 8}$ was regarded as the key intermediate, which produced reactive electrophilic iminium ion 19 through $\mathrm{H}$ and $\mathrm{O}$ atom elimination (Scheme 5).

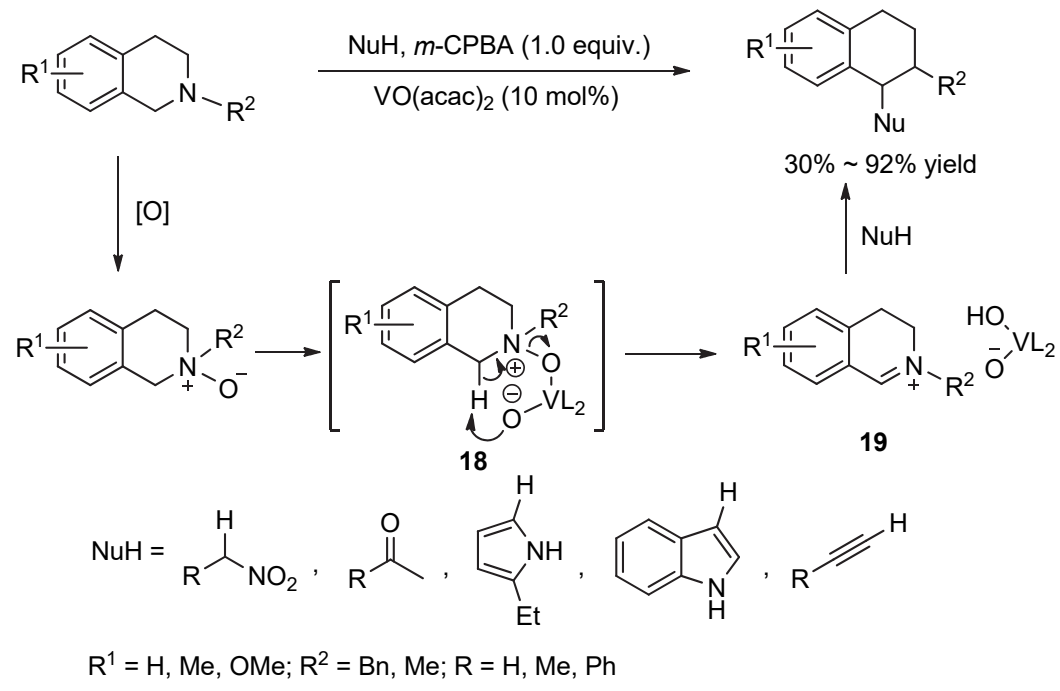

Scheme 5 VO(acac)2-promoted CDC reaction of THIQs 
In 2013, a diisopropanyl azodicarboxylate (DIAD)mediated fluoroalkylation of tertiary aliphatic amines with $\alpha$-fluorinatedsulfones was developed by $\mathrm{Hu}$ and coworkers $^{[11]}$ (Eq. 2). This method could also be successfully applied in the fluoroalkylation of amines with ether and hydroxyl functional groups. In addition, all the reactions showed high regioselectivity and only methyl groups were fluoroalkylated.

$$
\begin{aligned}
& \mathrm{R}^{\prime} \\
& \mathrm{R}^{1}, \mathrm{R}^{2}, \mathrm{R}^{3}=\text { alkyl; } \mathrm{X}=\mathrm{SO}_{2} \mathrm{Ph}, \mathrm{CO}_{2} \mathrm{Et}
\end{aligned}
$$

In 2015, a heterogeneous CDC reaction of tertiary amines using a zero-valent nanoporous gold (AuNPore) catalyst was developed by Jin's group. ${ }^{[12]}$ AuNPore was reused for ten cycles without any loss of activity and leaching of gold atoms. In addition to nitroalkanes, they studied the AuNPore-catalyzed CDC reactions of THIQs with various nucleophiles by the use of method A (Scheme 6).<smiles>[R]C([IH+])[N+](=O)[O-]</smiles>

$$
\begin{aligned}
& \frac{\text { AuNPore }(5 \mathrm{~mol} \%), 24 \mathrm{~h}}{\text { Method } \mathrm{A}: \mathrm{O}_{2}(101 \mathrm{kPa}), 80^{\circ} \mathrm{C} \text {, }} \\
& 70 \% \sim 99 \% \text { yield }
\end{aligned}
$$
$48 \% \sim 99 \%$ yield<smiles>[R]C(C1c2ccccc2CCN1[R])[N+](=O)[O-]</smiles>

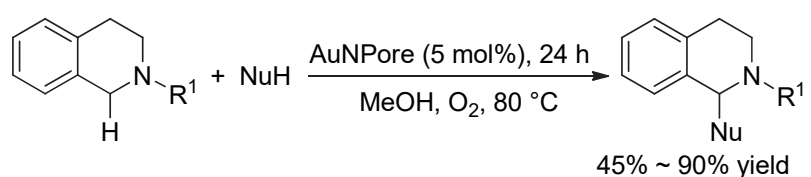

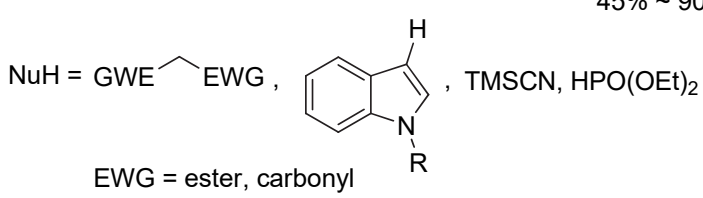

$\mathrm{R}^{1}=$ aryl, alkyl; $\mathrm{R}^{2}=$ alkyl

Scheme 6 AuNPore-catalyzed CDC reactions of THIQs

In 2017, Kim and coworkers ${ }^{[13]}$ developed a diethyl azodicarboxylate (DEAD)-promoted decarboxylation and oxidative coupling reaction of THIQs with $\beta$-keto acids to prepare the $\mathrm{C}(1)$-acylmethylated $N$-phenyl THIQs. The yields of the products were between $55 \% \sim 80 \%$ (Eq. 3 ).

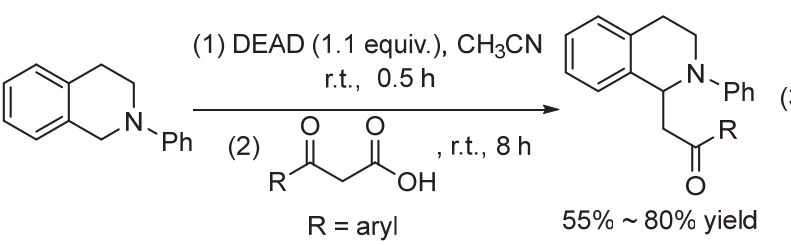

The choice of oxidants is an artistic process in these
CDC reactions as they perform dehydrogenation from $\mathrm{N}$-alkylamines to produce key intermediates of iminium ions. Recently, by using a novel tropylium salt as oxidant, Nguyen's group ${ }^{[14]}$ developed an efficient oxidative functionalization of THIQs at the $\mathrm{C}(1)$ position in the presence of nucleophiles or organometal reagents ( $\mathrm{Li}, \mathrm{Zn}, \mathrm{Mg}$ ). The oxidation reaction proceeded through a hydride abstraction to produce a key intermediate iminium salt $\mathbf{2 0}$ and a byproduct cycloheptatriene 21 (Scheme 7).

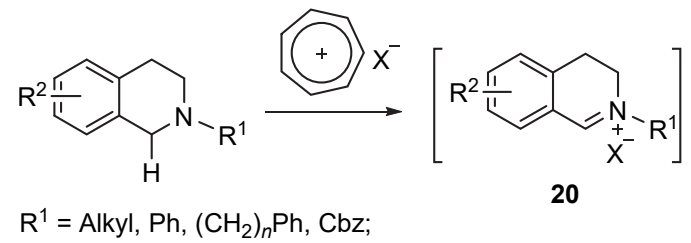
$\mathrm{R}^{2}=\mathrm{H}, \mathrm{OMe} ; \mathrm{X}=\mathrm{Br}, \mathrm{BF}_{4}, \mathrm{BPh}_{4}$
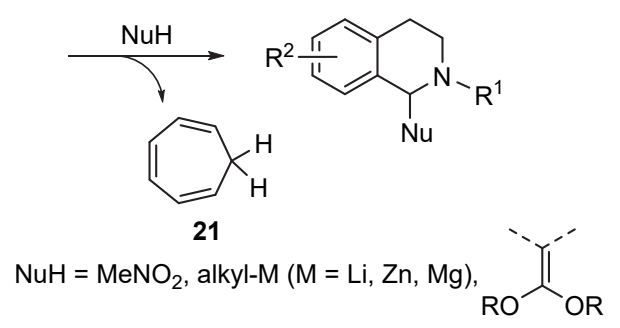

Scheme 7 Tropylium salt-mediated reaction

Besides organolithium, organomagnesium and organozinc reagents in Nguyen's work, triorganoindium reagents were also employed in the coupling reaction of THIQs. Recently, Sarandeses's group ${ }^{[15]}$ developed a CDC reaction of triorganoindium reagents with THIQs in the presence of $\mathrm{Ph}_{3} \mathrm{CBF}_{4}$ as an oxidant. In contrast, DDQ and phenyliodine(III) bis(trifluoroacetate) (PIFA) were almost entirely ineffective. They noted that the use of tri(4-methoxyphenyl)indium and tribenzylindium gave higher yield, which could reach 93\% (Eq. 4). This method was applied to the synthesis of the alkaloid nuciferine.

$$
\begin{aligned}
& \mathrm{N}_{-\mathrm{Cbz}}+\mathrm{R}_{3} \mathrm{In} \frac{\mathrm{Ph}_{3} \mathrm{CBF}_{4}(110 \mathrm{~mol} \%)}{\mathrm{CH}_{2} \mathrm{Cl}_{2} / \mathrm{THF}(\mathrm{V}: \mathrm{V}=4: 1)} \\
& \mathrm{R}=\text { aryl, heteroaryl, alkynyl, alkyl r.t., } 16 \mathrm{~h} \\
& \mathrm{R}^{1}=\mathrm{H}, \mathrm{OMe} \\
& \text { 54\% 93\% yield }
\end{aligned}
$$

Kumar and coworkers ${ }^{[16]}$ reported a CDC reaction of $N$-aryl THIQs with various nucleophiles catalyzed by the cobalt(II) $/ N$-hydroxyphthalimide (NHPI). The cobalt(II) is inexpensive and easily available. They tested 42 nucleophiles, and the alkylation, arylation, phosphorylation, cyanation and amidation of THIQs have been realized respectively. They carried out the reaction in the absence of nucleophiles and found the formation of the iminium ion, which strongly support that the reaction goes through an iminium ion intermediate (Eq. 5). 


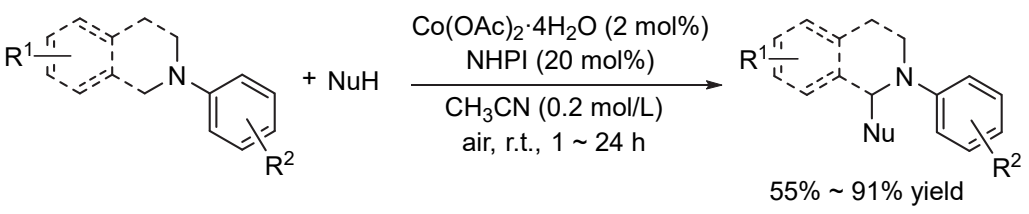

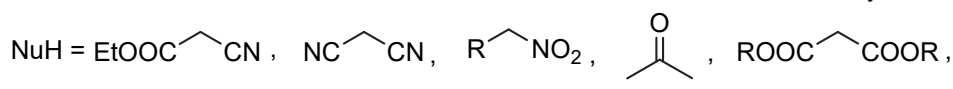

$$
\begin{aligned}
& \underbrace{2}_{O} \\
& \mathrm{R}^{1}=\mathrm{H}, \mathrm{OMe} ; \mathrm{R}, \mathrm{R}^{\prime}=\mathrm{alkyl} ; \mathrm{R}^{2}=\mathrm{H}, \mathrm{Me}, \mathrm{OMe}, \mathrm{CN}, \mathrm{Cl}, \mathrm{O}_{\mathrm{O}}^{\mathrm{s}} \mathrm{M}^{\mathrm{O}}
\end{aligned}
$$

Peroxides and oxygen (air) were frequently utilized as oxidants in CDC reactions. Recently, $\mathrm{Xu}$ and coworkers ${ }^{[17]}$ developed an oxidative $\alpha$-trichloromethylation of tertiary amines, which can be completed almost instantaneously at room temperature by using DDQ as an oxidant. The yield of this reaction was good to excellent. The trichloromethylated products were transformed into $\beta, \beta$-dichloroamines, enamines and $\alpha$-amino acid esters under operationally simple conditions (Scheme 8).

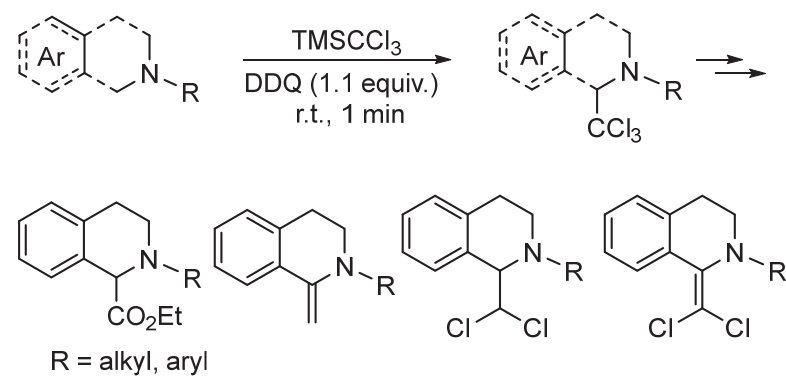

Scheme 8 Trichloromethylation of tertiary amines

The asymmetric CDC reaction between $\mathrm{N}$-phenyl-tetrahydroisoquinoline and ketone or aldehyde usually needs excess amounts of oxidants, and most of the catalyst amines are unstable under the oxidative conditions. In 2017, Wu and Luo's group ${ }^{[18]}$ addressed this issue by the use of a hydrogen transfer strategy. In their reaction, substoichiometric amounts of a nitro-compound acts as the hydrogen acceptor, which circumvents the need for extra oxidants and avoids the oxidative consumption of the amine catalyst under harsh oxidation conditions. The good syn-diastereoselectivity was achieved in the reactions of $N$-phenyl THIQ with cyclic ketones. The oxidation of $*\left[\mathrm{Ru}(\mathrm{bpy})_{3}\right]^{2^{+}}$to $\left[\mathrm{Ru}(\mathrm{bpy})_{3}\right]^{3^{+}}$by $\left[\mathrm{Co}^{\mathrm{III}}\right]$ was occurred by visible-light irradiation. The iminium cation 22 was generated through commonly SET and hydrogen atom abstraction (HAT) or $\mathrm{e} / \mathrm{H}^{+}$transformation process. Then $\left[\mathrm{Co}^{\mathrm{II}}\right]$ trapped the electron and proton to form $\left[\mathrm{Co}^{\mathrm{I}}\right]$ and $\left[\mathrm{Co}^{\mathrm{III}}-\mathrm{H}\right]$, which hydrogenated $m-\mathrm{NO}_{2} \mathrm{C}_{6} \mathrm{H}_{4} \mathrm{COOH}$ to complete the cycle. Simultaneously, the reaction between the primary amine $\mathbf{2 3}$ and ketone $\mathbf{2 4}$ generated an enamine intermediate 25. Then it reacted with 22 to produce the imine intermediate $\mathbf{2 7}$ via transition-state $\mathbf{2 6}$. The final product $\mathbf{2 8}$ was formed by the hydrolysis of $\mathbf{2 7}$ and the amine catalyst was regenerated (Scheme 9).

\subsubsection{Alkylation of alkenes}

By the use of $N, N$-dimethyl anilines and electron-deficient alkenes, Miura and coworkers ${ }^{[19]}$ described a direct oxidative cyclization for the synthesis of tetrahydroquinolines. Besides the methyl group, the ortho- $\mathrm{C}-\mathrm{H}$ bond of anilines participated the cyclization. The reaction occurred under a $\mathrm{CuCl}_{2} / \mathrm{O}_{2}$ catalysis and a radical mechanism was proposed by authors (Scheme 10). The substrate 29 first transferred to a radical cation 30 through a single electron transfer (SET) process under copper-catalyzed conditions. Then an $\alpha$-amino radical $\mathbf{3 1}$ was generated by the deprotonation of 30. Subsequently, an electrophilic radical addition to maleimide $\mathbf{3 2}$ and cyclization onto the aromatic ring occurred to generate the corresponding cyclohexadienyl radical 33, which was finally rearomatized to the product 34 via the second electron transfer/proton elimination.

Soon after Miura's discovery, Guan's group ${ }^{[20]}$ developed a dehydrogenative $[4+2]$ intramolecular cycloaddition of tertiary anilines and enamides using the combination of iron chloride and tert-butyl hydroperoxide (TBHP) under mild conditions with good functional group tolerance (Scheme 11). The authors suggested that the corresponding tetrahydroquinolines compounds could be obtained in good yields regardless of the electrical groups on the enamides. But $N, N$-diethylaniline and aliphatic amines were inactive in this reaction. One stepwise and a concerted pathway were proposed by authors. Iminium ion $\mathbf{3 6}$ was readily generated from substrate $\mathbf{3 5}$ by the use of the catalytic system Fe/TBHP. In the stepwise pathway, nucleophilic addition of enamide $\mathbf{3 7}$ to iminium ion $\mathbf{3 6}$ gave intermediate 38, which undwent a subsequent intramolecular cyclization and deprotonation to give the final product 39 . In another pathway, the intermediate $\mathbf{4 0}$ was directly formed through a concerted transition state. Upon deprotonation, intermediate $\mathbf{4 1}$ transformed to final product $\mathbf{3 9}$. The authors further suggested that the stepwise pathway (path a) was favorable and it was supported by the result of density functional theory (DFT) calculations. 


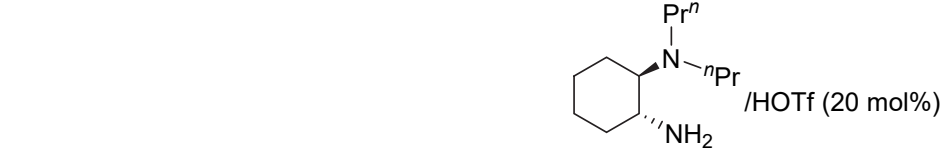

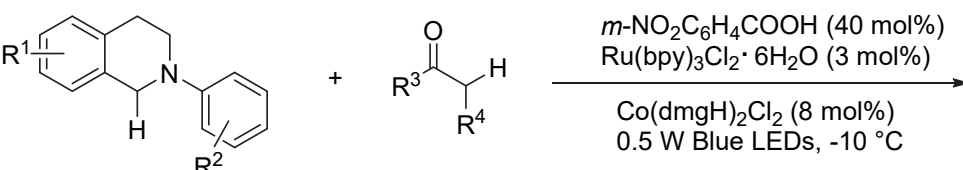

$\mathrm{R}^{1}=\mathrm{H}, \mathrm{OMe} ; \mathrm{R}^{2}=\mathrm{H}$, halogen, Me, OMe; $\mathrm{R}^{3}, \mathrm{R}^{4}=$ alkyl<smiles>CN=C1CCCC[C@H]1C1c2ccccc2CN1Pc1ccccc1</smiles>

27

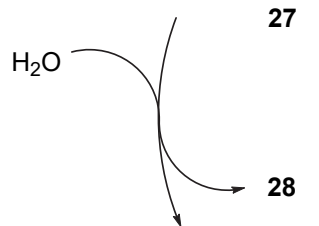<smiles>CCN(C(C)C)N([OH+])C1CCCC[C@H]1N</smiles>

23

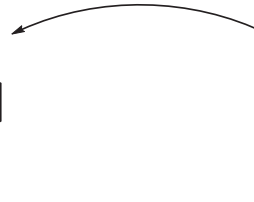

Primary amine

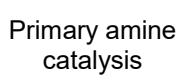

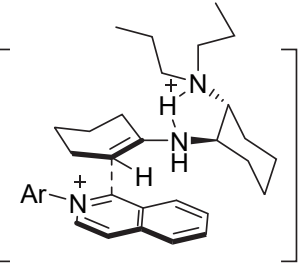

$(2 S, 3 S)$

favored

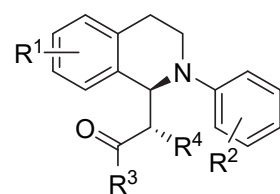

$48 \% \sim 92 \%$ yield $25 \% \sim 99 \%$ ee $2: 1 \sim 19: 1 d . r$

vs.

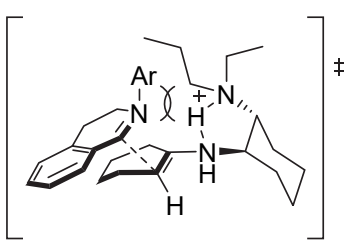

$(2 R, 3 R)$

sterically and electrostatically disfavored (e) $\mathbb{H}^{+}$

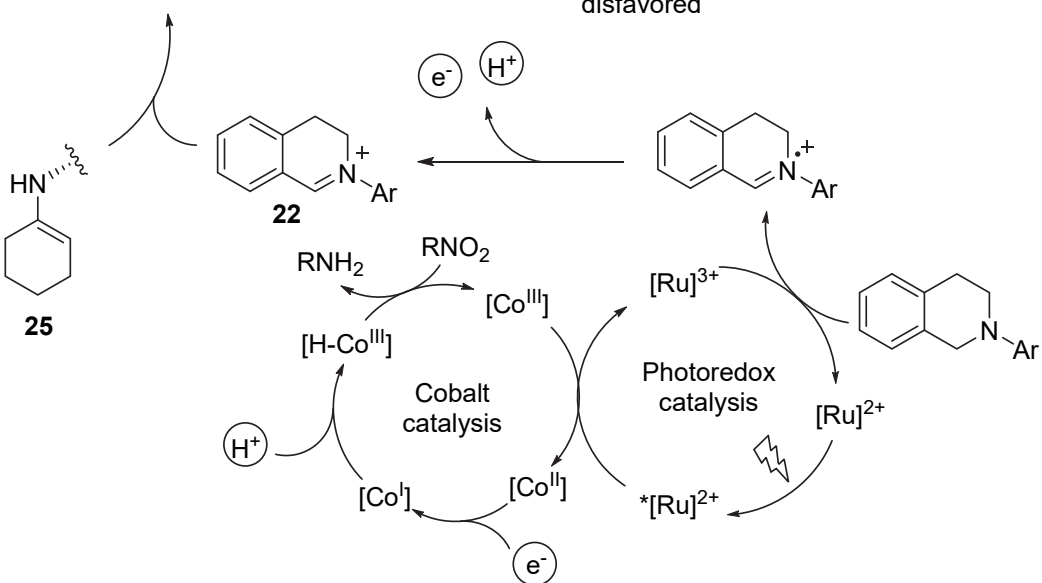

Scheme 9 Asymmetric CDC reaction between $N$-phenyl THIQs and ketones

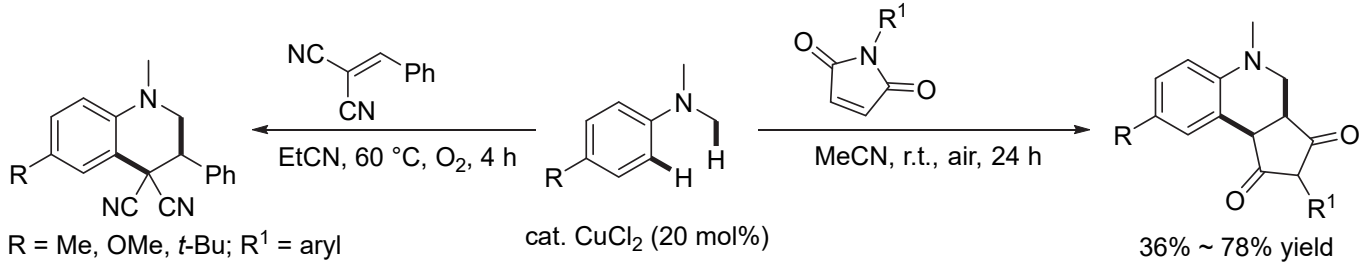

$44 \% \sim 50 \%$ yield

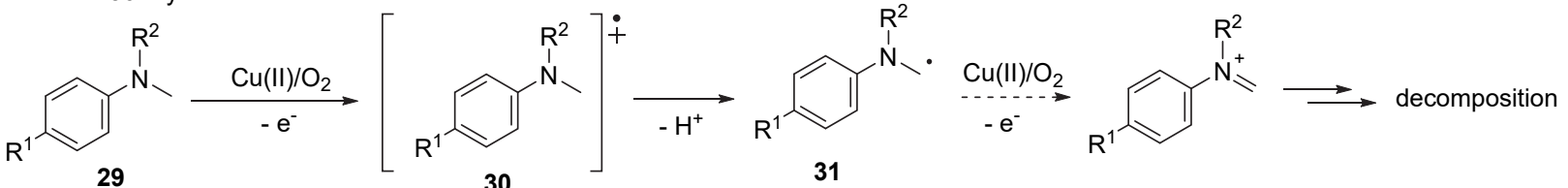

29<smiles>[R]c1ccc2c(c1)C1C(=O)N([R])N([R])C(=O)C1N2[R]</smiles>

34<smiles>[R]c1ccc(N([R2])CC2CC(=O)N([R])C2=O)cc1</smiles>

33

Scheme 10 Synthesis of tetrahydroquinolines 


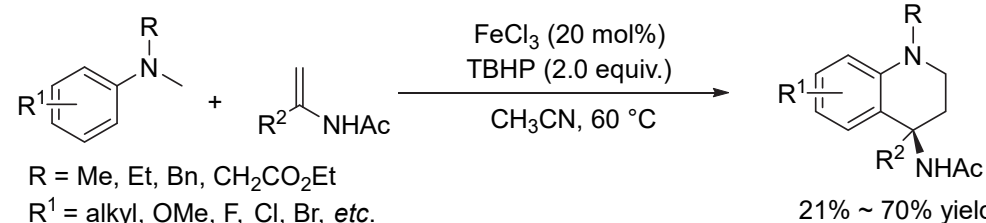

$\mathrm{R}^{2}=$ aryl, naphthyl, thienyl, pyridyl, alkyl, $\mathrm{H}, \mathrm{CO}_{2} \mathrm{Et}$<smiles>CN(CC(C)(F)F)c1ccccc1</smiles>

35

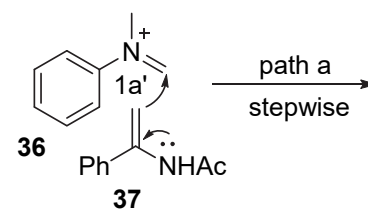

37

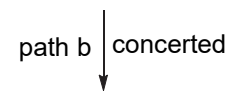<smiles>[Y]c1ccccc1C1(NC(=O)c2ccccc2)C=C[N+](C)=C1</smiles>

40<smiles>CN1CCC(c2ccccc2)C(=N)c2ccccc21</smiles><smiles>C[C+](C)NC1(c2ccccc2)CC[N+](C)=C2C=CC=CC21c1ccccc1</smiles>
$\mathrm{AcHN} \mathrm{Ph}$ 38<smiles>CC(C)NC1(c2ccccc2)CC[N+](C)=C2C=CC=CC21</smiles>

41<smiles>CN1CCC(c2ccccc2)([N+]([O-])([O-])c2ccccc2)c2ccccc21</smiles>

39

Scheme 11 Dehydrogenative $[4+2]$ intramolecular cycloaddition of tertiary anilines and enamides

In 2014, an organocatalytic asymmetric oxidative CDC of THIQs with $\alpha, \beta$-unsaturated $\gamma$-butyrolactams to generate Morita-Baylis-Hillman-type products was reported by Wang's group ${ }^{[21]}$ (Eq. 6). A bifunctional thiourea catalyst was used as the organocatalyst and DDQ as oxidant. The yield and the ee value were satisfactory.<smiles>[R]c1cc2c(cc1[R])CN([Z8])CC2</smiles>
$\mathrm{R}^{1}, \mathrm{R}^{2}=\mathrm{H}, \mathrm{OMe} ; \mathrm{R}^{3}=$ aryl

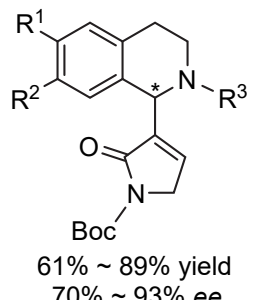<smiles>C=C[C@H]1CN2CC[C@H]1C[C@H]2[C@H](NC(=S)Nc1c(C)cc(C)cc1C)c1ccnc2ccc(OC)cc12</smiles>

\subsubsection{Alkylation of terminal alkynes}

In comparison with general alkanes and alkenes, terminal alkynes own active $\mathrm{C}-\mathrm{H}$ bonds. The $\mathrm{CDC}$ reaction of terminal alkynes has been gradually disclosed recently. In 2004, Li and coworkers ${ }^{[22]}$ reported the first asymmetric cross-dehydrogenation coupling (CDC) reaction of $N$-aryl tetrahydroisoquinoline using copper trifluoromethanesulfonate (CuOTf) as catalyst and chiral oxazoline as ligand. The enantioselective synthesis of tetrahydroisoquinoline derivatives with $\mathrm{C}(1)$ chiral carbon was realized with moderate yield. Only moderate and low ee values were realized by this method and a long reaction time of $2 \mathrm{~d}$ was needed (Eq. 7).

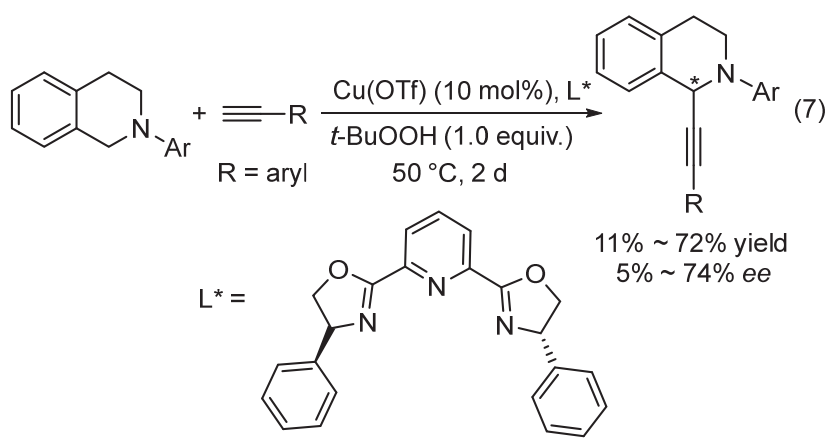

In 2008, an oxidative coupling reaction of tertiary aliphatic amines with alkynes was reported by Fu's group. ${ }^{[23]}$ By the use of radical initiator system ( $\mathrm{CuBr} / \mathrm{NBS})$, they prepared the propargylamines in moderate to low yields (Eq. 8). The authors found that the alkynylation selectively occurred on the methyl group rather than ethyl and benzyl groups because of the stereo effect for tertiary aliphatic amines. The general $N, N$-dimethyl anlines were not the suitable substrates in this reaction and only trace amounts of products were detected.

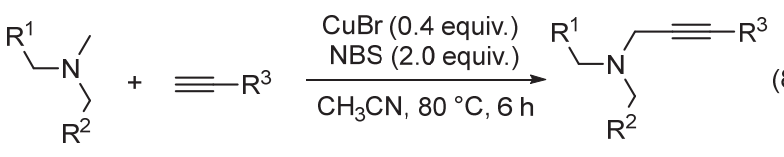

$\mathrm{R}^{1}, \mathrm{R}^{3}=$ aryl, alkyl; $\mathrm{R}^{2}=\mathrm{H}, \mathrm{Me}$

$29 \% \sim 65 \%$ yield

In 2014, Mizuno and coworkers ${ }^{[24]}$ developed the CDC reaction of terminal alkynes and tertiary amines to propargylamines using molecular oxygen as the terminal oxidant 
in the presence of $\mathrm{ZnBr}_{2}$ and a manganese oxide-based octahedral molecular sieve (OMS-2) (Eq. 9). This CDC reaction could be used to synthesize various kinds of structurally diverse propargylamines successfully, which have widely been utilized as synthetic intermediates for nitrogen-containing compounds. In addition, OMS-2 could easily be retrieved by simple filtration and be reused several times. This CDC reaction has a regioselectivity that the alkynylation exclusively occurred at the methyl positions.

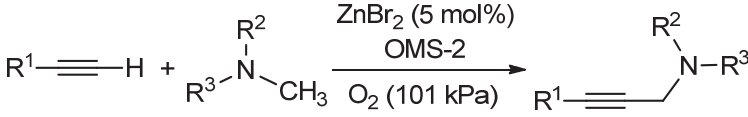

$$
\begin{aligned}
& \mathrm{R}^{1}=\text { aryl, alkyl; } \mathrm{R}^{2}, \mathrm{R}^{3}=\text { alkyl } \\
& 22 \% \sim 88 \% \text { yield }
\end{aligned}
$$

By using $\mathrm{CuBr}$ and ligand $\mathrm{L}$, Liu and coworkers ${ }^{[25]} \mathrm{de}-$ veloped a catalytic asymmetric $\mathrm{CDC}$ reaction of cyclic carbamates and terminal alkynes. The reaction provided high enantiocontrol and excellent functional group tolerance and displayed a wide range of substrates. Moreover, the synthesis of biologically active natural product emetine was present as the application of their methodology (Eq. $10)$.

$$
\mathrm{R}^{1}=\text { alkyl, halogen; }
$$

Feng's group ${ }^{[26]}$ focused on the $N, N^{\prime}$-dioxide ligands in the asymmetric synthesis in recent years. In 2017, they developed an efficient asymmetric aerobic oxidation of THIQs with terminal alkynes using $\mathrm{Zn}(\mathrm{II}) / \mathrm{Fe}(\mathrm{II}) / N, N^{\prime}-$ dioxide-metal complex catalyst under the mild condition with $\mathrm{O}_{2}$ as the sole oxidant. The yield and enantioselectivity were excellent. This is also a breakthrough that chiral $N, N^{\prime}$-dioxide-metal complex was used for the activation of unfunctionalized alkynes (Eq. 11).

In 2018, Shi and coworkers ${ }^{[27]}$ reported a method of iron-catalyzed alkynylation of tertiary aliphatic amines with 1-iodoalkynes in the presence of tert-butyl hydroperoxide (TBHP-decane) as the oxidant (Eq. 12).

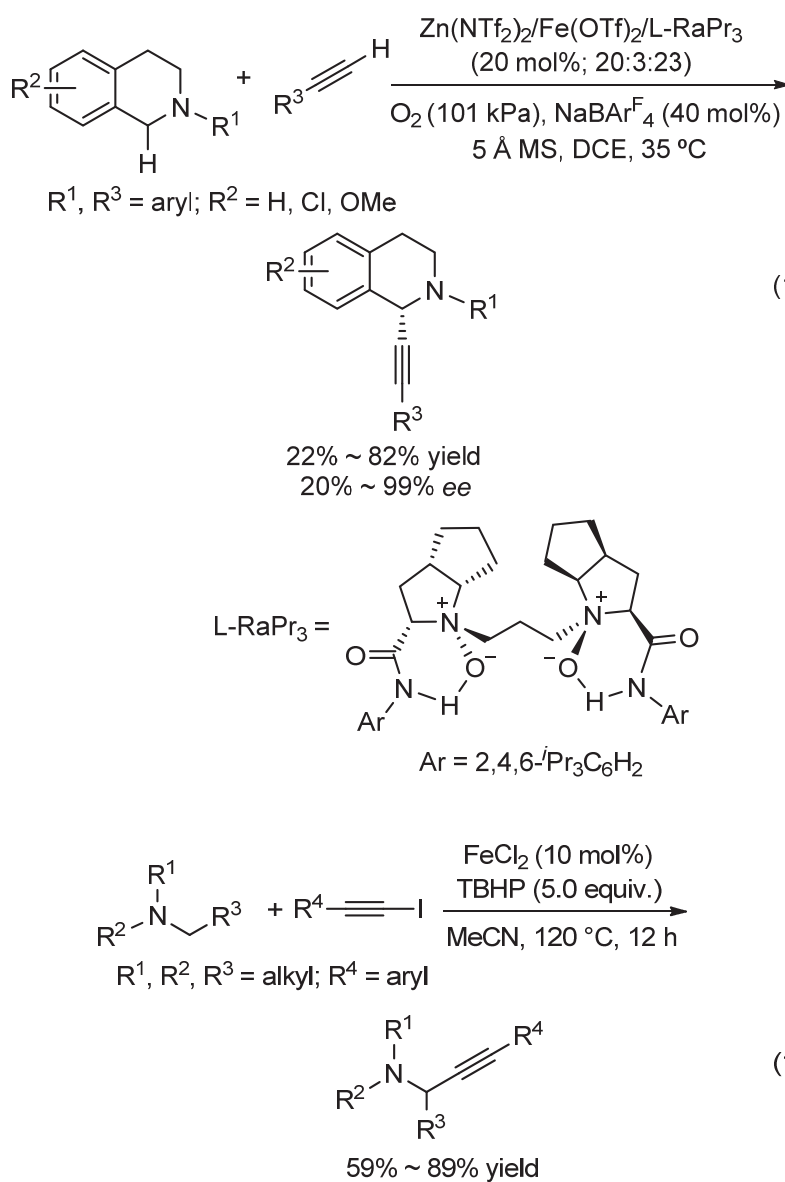

\subsubsection{Alkylation of arenes and heterocycles}

After Li's study on the reaction of tertiary amines with nitroalkanes ${ }^{[5]}$ or terminal alkynes, ${ }^{[22]}$ they further used indoles as nucleophilies in $\mathrm{C}-\mathrm{C}$ coupling reactions of THIQs (Eq. 13). They found the $\mathrm{C}(3)$ position of indole reacted with the $\mathrm{C}(1)$ position of THIQs by $\mathrm{CuBr} / \mathrm{TBHP}$ catalysis, and the product was obtained in medium to excellent yields under mild conditions in the absence of solvent. The substituents on the indoles have no obvious effect on the reaction. ${ }^{[28]}$

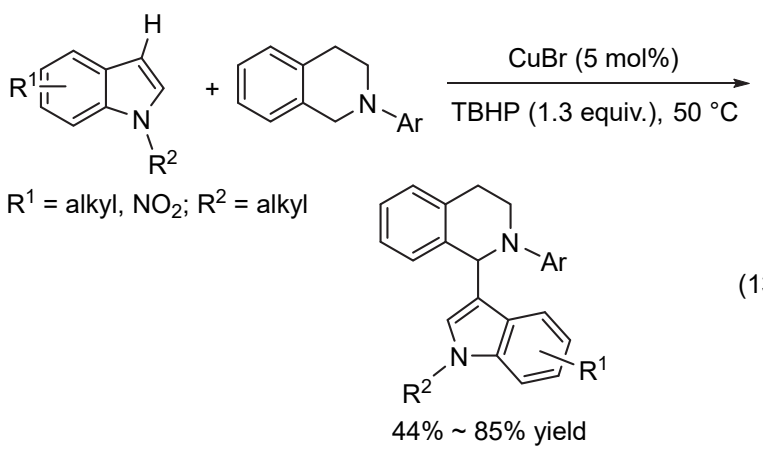

In 2008, Li's group ${ }^{[29]}$ further developed a coupling reaction of THIQs with arylboronic acid using copper bromide as catalyst in the presence of TBHP or oxygen. They also examined the asymmetric oxidative arylation of 
$N$-phenyl THIQ by the use of ligand PhPyBox, but the ee value was low (Scheme 12). The authors presented two possible pathways for this transformation. In pathway A, an $\beta$-hydroxy amine intermediate $\mathbf{4 3}$ was generated from the reaction of iminium ion $\mathbf{4 2}$ and water. It could either be further oxidized to the observed amide 44 byproduct or react with arylboronic acid to form boronate $\mathbf{4 5}$. The final product 46 was formed through an addition-eliminationtype reaction of $\mathbf{4 2}$ and arylboronic acid. In another pathway, iminium ion $\mathbf{4 2}$ reacted directly with arylboronic acid to produce the final product $\mathbf{4 6}$.
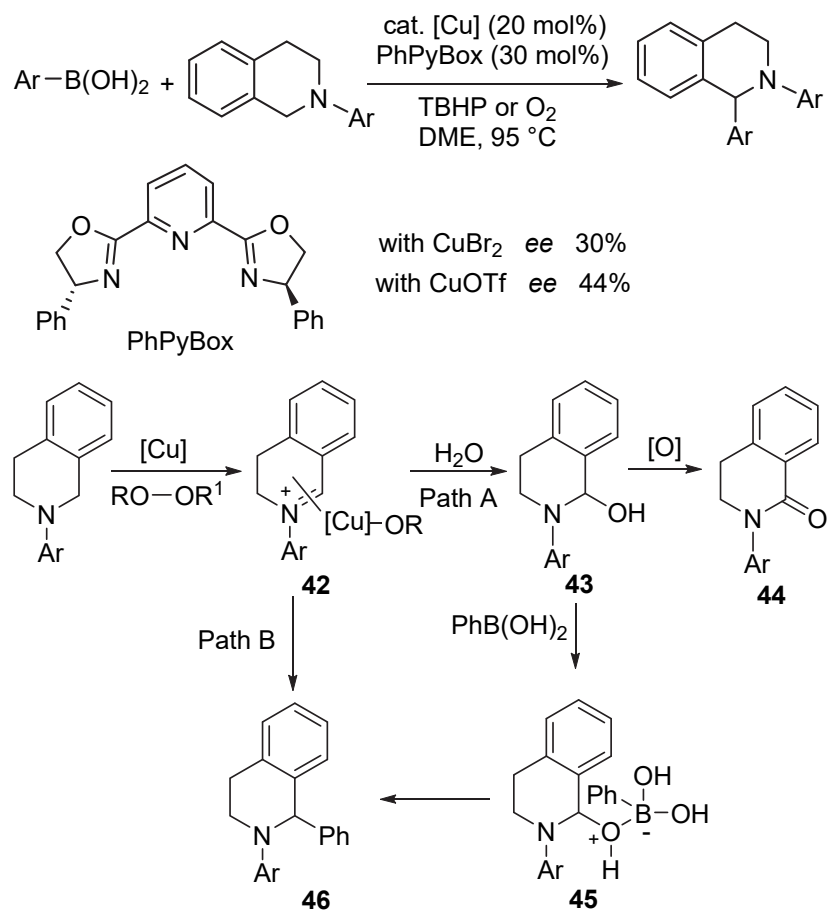

Scheme 12 Reaction of arylboronic acid and THIQs

Zhang and coworkers ${ }^{[30]}$ developed an alkylation reaction of $N$-heterocycles with $N, N$-dimethylanilines under the copper-promoted conditions. In this reaction, environmentally benign molecular oxygen or air served as the oxidant. Among the $N$-heterocycles, indolizine and indole were particularly investigated. The authors found that the $\mathrm{C}(3)$-alkylation and $\mathrm{N}$-alkylation were simultaneously realized in the reaction of $N$-free indoles (Scheme 13).

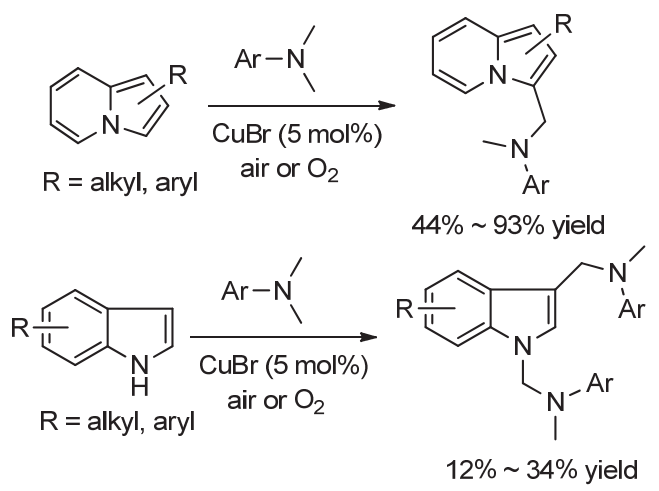

Scheme 13 Reaction of $N$-heterocycles and $N, N$-dimethylanilines
In 2013, Doyle and coworkers ${ }^{[31]}$ developed a procedure for the aerobic oxidation of tertiary anilines catalyzed by iron(III) chloride (Scheme 14). They also proposed an oxidative Mannich reaction mechanism like those using TBHP as oxidant.

$$
\text { , Alkyl }
$$

Scheme $14 \mathrm{FeCl}_{3}$-catalyzed aerobic oxidation of tertiary anilines

In 2013, Weaver and coworkers ${ }^{[32]}$ reported a reaction of tertiary aliphatic amines with 2-chloroazole derivatives. The reaction is promoted by the catalytic amount of tris- $f a c-\operatorname{Ir}(\text { ppy })_{3}$, with blue light irradiation and takes place under mild and convenient conditions (Eq. 14). By the use of this method, they prepared a previously unknown analogue of Nizatidine differing at the carbinamine side chain from commercially available components in fewer steps with greater structural diversity than previously investigated.

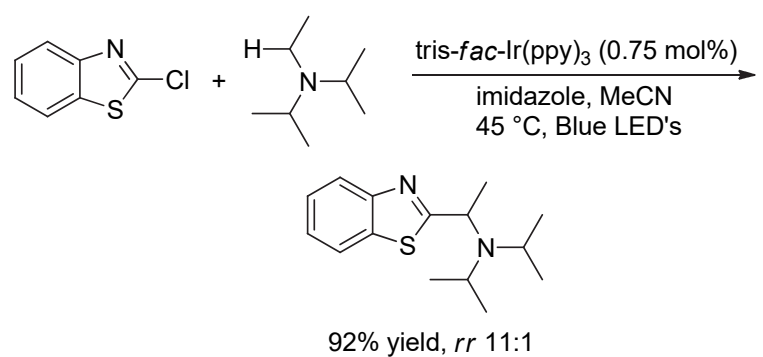

The metal-free CDC reactions of THIQs are very attractive. By the use of $\mathrm{I}_{2} /$ TBHP or $\mathrm{I}_{2} / \mathrm{O}_{2}$, Prabhu and coworkers $^{[33]}$ explored the metal-free CDC reaction of THIQs. A variety of nucleophiles were compatible under the green conditions and $\mathrm{C}-\mathrm{C}, \mathrm{C}-\mathrm{N}, \mathrm{C}-\mathrm{P}$ and $\mathrm{C}-\mathrm{O}$ bonds were constructed successfully (Scheme 15). The intermediates 47, 48 and 49 were detected by electrospray ionization (ESI) mass spectrometric analysis. Moreover, 48 was further isolated and characterized by ${ }^{1} \mathrm{H}$ NMR, ${ }^{13} \mathrm{C}$ NMR spectroscopic and mass spectrometric analysis. The authors presented a pathway based on these results.

In 2013, Liu's group ${ }^{[34]}$ achieved the asymmetric synthesis of 2-substituted-tetrahydroisoquinolin-1-yl glycines by $\mathrm{CDC}$ reaction of THIQs with chiral nickel(II)glycinate. 


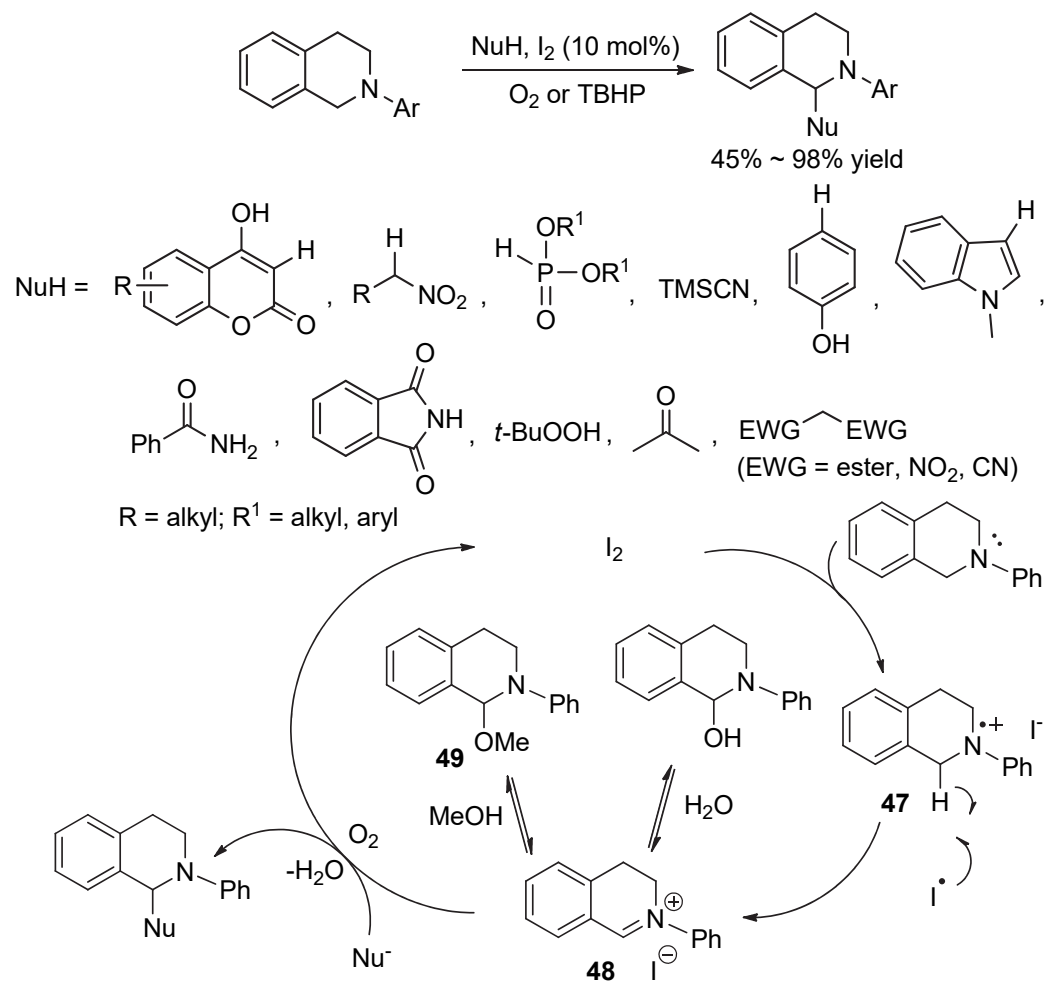

Scheme 15 Metal-free CDC reaction of THIQs with $\mathrm{I}_{2} / \mathrm{TBHP}$ or $\mathrm{I}_{2} / \mathrm{O}_{2}$

The nickel(II) complexes could be decomposed into 2-substituted-tetrahydroisoquinolin-1-yl glycine derivatives. The reaction cycle process is shown in Scheme 16 . The advantage of this reaction was that $(S)$-BPB could be recycled in large quantities. The yield was excellent and the ee value was high.<smiles>O=C1C=C(c2ccccc2)N2N(Cc3ccccc3)C(=O)CN3CCC[C@H]1C(=O)N2c1ccccc13</smiles>

$(S)$

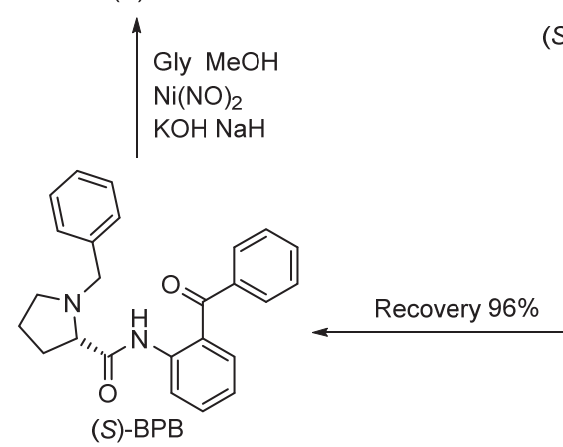

(S)-BPB

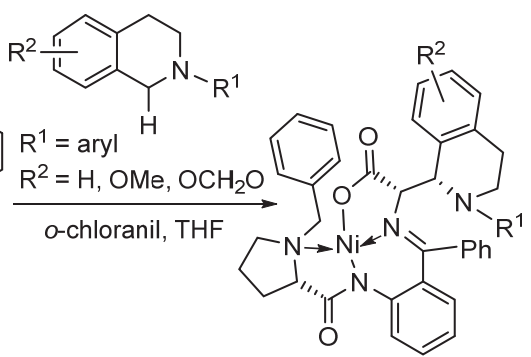

(S) $\left(2 S, 2\left(1^{\prime} S\right)\right)$

(1) EDTA

$\mathrm{N}_{2} \mathrm{H}_{4} \mathrm{H}_{2} \mathrm{O} / \mathrm{EtOH}$

(2) $6 \mathrm{~mol} / \mathrm{L} \mathrm{HCl}$

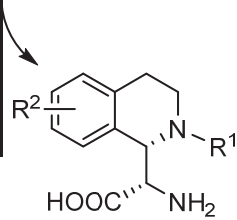

$(2 S, 2(1 ' S))$
Scheme 16 Asymmetric synthesis of 2-substituted-tetrahydroisoquinolin-1-yl glycines

Wang's group ${ }^{[35]}$ developed CDC reaction of THIQ and $5 \mathrm{H}$-oxazol-4-ones with $\mathrm{CuBr}$ under air atmosphere condi- tions and metal-free $\mathrm{PhI}(\mathrm{OAc})_{2}$-oxidated conditions. The author suggested the pathway similar to the work of Klussmann ${ }^{[9]}$ as shown in Scheme 17.

The alkylation of inert aromatic $\mathrm{C}-\mathrm{H}$ by using $N, N$-dimethyl aniline is rare, although this process was frequently observed on the heteroaromatic $\mathrm{C}-\mathrm{H}$ bond such as indoles and indolizines noted above. Recently, Patureau and coworkers ${ }^{[36]}$ revealed that the divalent copper reagents could be used as promotors in the orthoaminomethylation of phenols and anilines (Eq. 15). Compared to traditional Mannich reaction, this method has the advantages of wide substrates scope and high chemical selectivity, and avoids the preactivation process. The authors suggested that the catalyst dichloro(1,10-phenanthroline) copper(II) $\left(\mathrm{L}^{1} \mathrm{CuCl}_{2}\right)$ and the oxidant di-tert-butyl peroxide (DTBP) start this radical reaction.

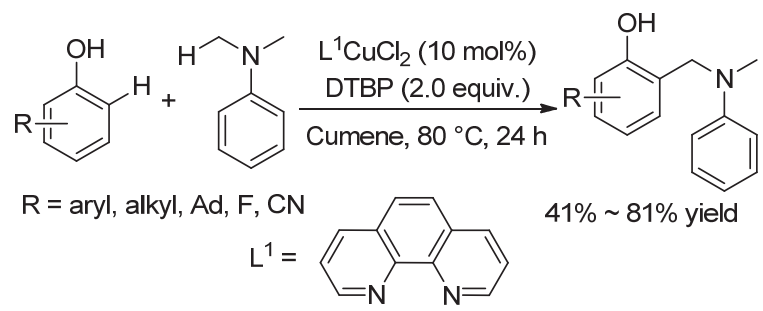

A visible-light-promoted CDC reaction of THIQs or $\mathrm{N}, \mathrm{N}$-dimethylanilines with $a z a$-heterocycles was developed using a catalytic amount of rose bengal as photosensitizer under aerobic conditions by Hajra and coworkers. ${ }^{[37]}$ The advantage of this reaction was metal free, mild conditions, wide substrates scope and use of organophotocatalyst (Eq. 16). 


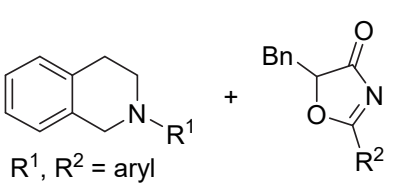

$\mathrm{R}^{1}, \mathrm{R}^{2}=$ aryl
$\mathrm{CuBr}(10 \mathrm{~mol} \%)$, THF, air, $50{ }^{\circ} \mathrm{C}$ $49 \% \sim 87 \%$ yield
or $\mathrm{Phl}(\mathrm{OAc})_{2}(1.2$ equiv.), THF, r.t.
$72 \% \sim 90 \%$ yield

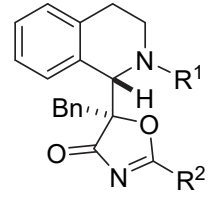

$\mathrm{Phl}(\mathrm{OAc})_{2}$

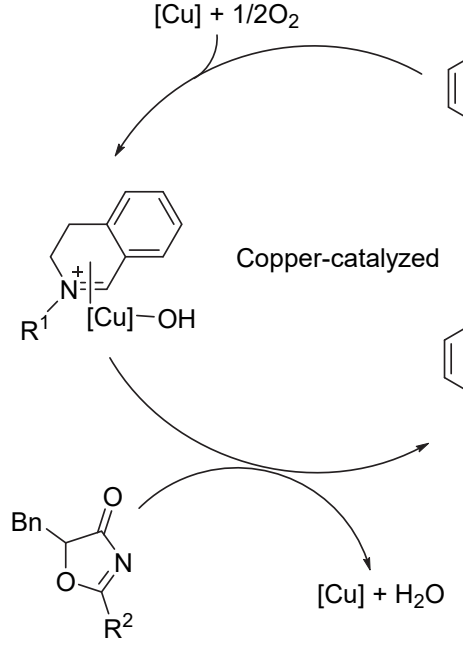<smiles>[R]N1Cc2ccccc2C1</smiles><smiles>[R]OC1CCc2ccccc2C1</smiles>

etal-free<smiles>C1CCOCC1</smiles>

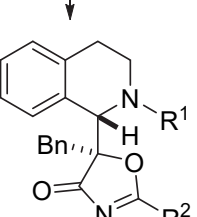
$\mathrm{Phl}$

Scheme 17 Oxidative cross-dehydrogenative coupling between $\mathrm{N}$-aryl tetrahydroisoquinolins and $5 H$-oxazol-4-ones

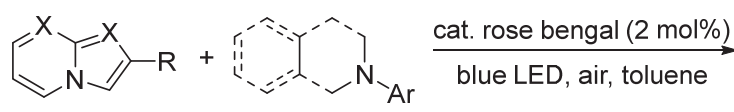

$\mathrm{X}=\mathrm{CH}$ or $\mathrm{N} ; \mathrm{R}=$ alkyl, aryl

$$
\text { 74\% } \sim 91 \% \text { yield }
$$

In 2019, De and coworkers ${ }^{[38]}$ investigated a CDC reaction photocatalyzed by $2 \mathrm{D}-\mathrm{MoS}_{2}$ synchronized with hydrogen evolution reaction. They explored the process of photocatalytic oxidation-reduction cycles (Scheme 18). The reaction resulted in good to excellent yield of the corresponding product under visible light irradiation at room temperature.

\subsubsection{Alkylation of heteroatoms $(\mathrm{N}, \mathrm{P})$}

In 2007, an amidation of $\mathrm{C}\left(\mathrm{sp}^{3}\right)-\mathrm{H}$ bonds adjacent to the nitrogen atom has been developed by $\mathrm{Fu}$ and coworkers. ${ }^{[39]}$ They found that the reaction of $N, N$-dimethylaniline with amides produced dehydrogenative coupling products by the use of the combination of $\mathrm{CuBr} /{ }^{t} \mathrm{BuOOH}$. Interestingly, $N$-methyl- $N$-phenylaniline could also serve as a partner, which gave a major coupling product 50 through unusual dephenylation (Scheme 19). One example of intramolecular amidation was also presented.

In 2012, a CDC reaction of $N, N$-dimethylanilines to form $\mathrm{C}-\mathrm{N}$ and $\mathrm{C}-\mathrm{C}$ bonds was disclosed by our group $^{[40]}$. By the use of $\mathrm{N}-\mathrm{H}$ free indoles as coupling partners, the $N$-alkylation and $\mathrm{C}(3)$-acylation of indoles were simultaneously achieved using a clean and friendly KI/TBPB system (Scheme 20). We also proposed a

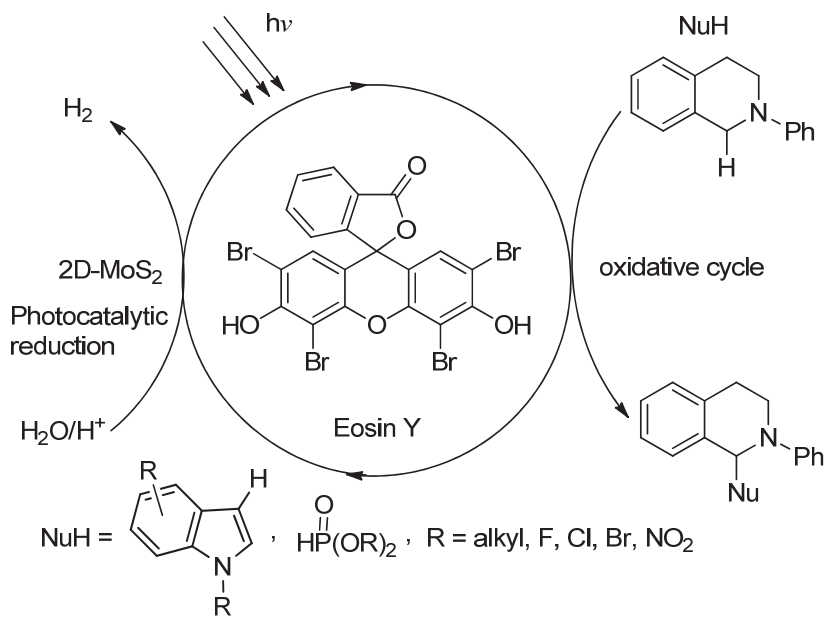

Scheme 18 2D-MoS 2 -photocatalyzed CDC reaction of TIHPs

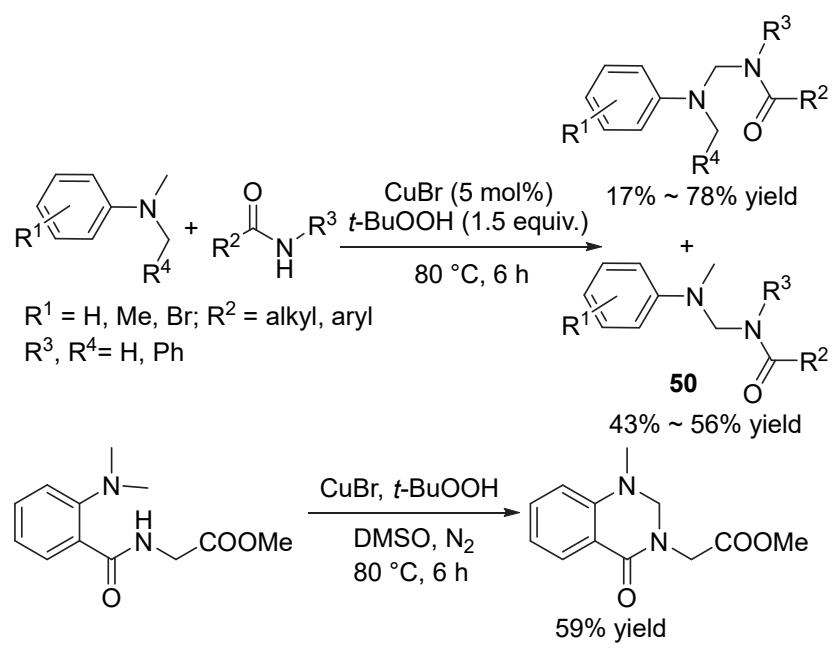

Scheme 19 Amidation of tertiary amines 

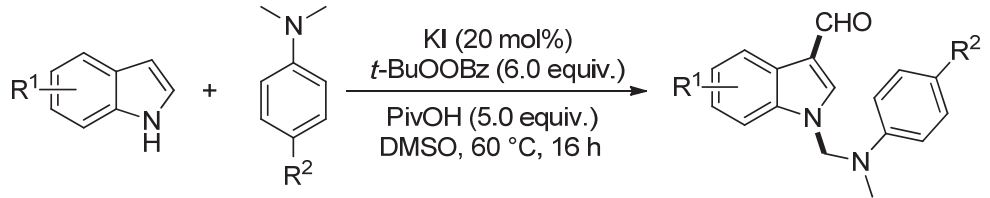

$\mathrm{R}^{1}, \mathrm{R}^{2}=$ alkyl<smiles>CN([Al])Cn1cc(/C=N/[Ga])c2ccccc21</smiles>

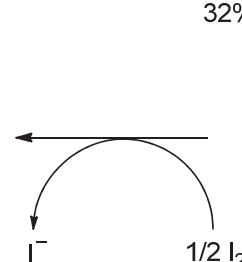

$32 \% \sim 91 \%$ yield<smiles>CCCCN(C)C</smiles>

51

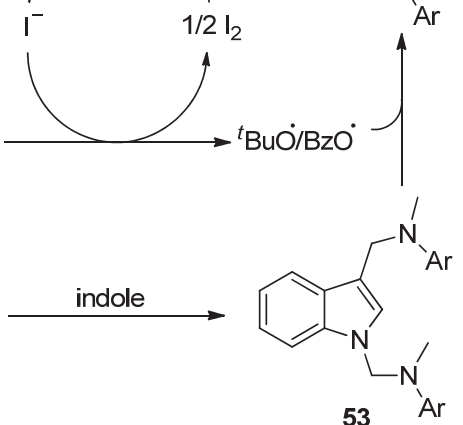

Scheme $20 N$-Alkylation and C(3)-acylation of indoles

mechanism for this bifunctionalization of indole. First, a SET process between TBPB and iodine ion occurred to give either tert-butyloxy or benzoyloxy radical, which abstracts an $\alpha$-hydrogen of $N, N$-dimethylaniline and forms the intermediate 51. Iminium ion $\mathbf{5 2}$ was then generated from the oxidation of 51. Nucleophilic attack by an indole derivative resulted in dialkylated intermediate 53. The final product 54 was formed by similar oxidation and hydrolysis.

Recently, an aerobic cross-dehydrogenative coupling reaction of $N, N$-dimethyl aniline using $\mathrm{CuBr}$ as a catalyst under room temperature was reported by Jain and coworkers. ${ }^{[41]}$ Air was used instead of TBHP, and various substrates including oxindoles, isatins, lactams, benzamide, succinimide and phthalimide were suitable substrates, leading to the formation of the corresponding amidated or imidated products (Eq. 17).

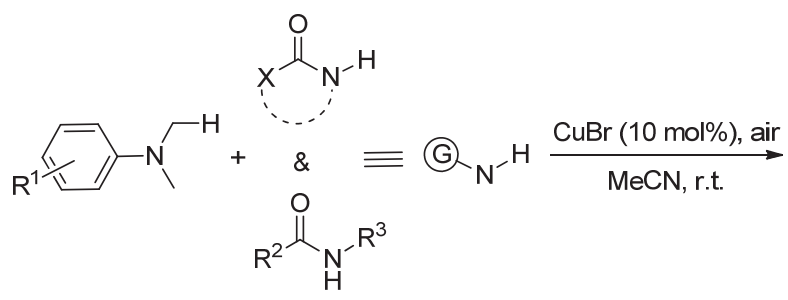

$\mathrm{R}^{1}=\mathrm{H}, \mathrm{Me}, \mathrm{OMe}, \mathrm{F}, \mathrm{Cl}, \mathrm{Br} ; \mathrm{R}^{2}, \mathrm{R}^{3}=$ aryl, alkyl<smiles>[R]c1ccc(N(C)CNc2ccco2)cc1</smiles>

aniline was reported by Meng and coworkers ${ }^{[42]}$ (Eq. 18). The $\mathrm{KI} /{ }^{t} \mathrm{BuOOH}$ combination is simple and compatible with air and moisture in comparison with the previously reported metal catalysts. However, the large excess of anilines was used in this method.

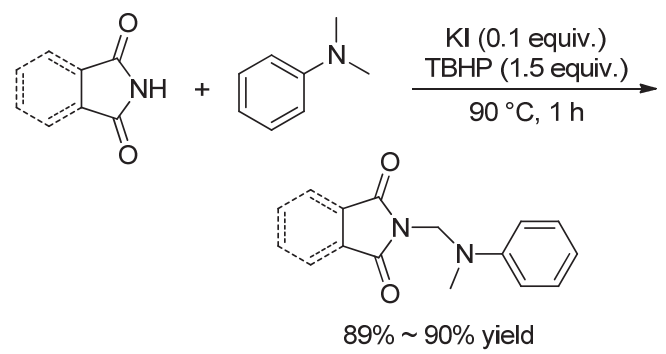

This similar process could also be achieved using $N$-acetyloxyphthalimide as partners. A visible-light/ $\mathrm{Ru}$ (bpy) ${ }_{3} \mathrm{Cl}_{2}$-promoted $\mathrm{C}-\mathrm{H}$ activation of $N, N$-dimethylanilines via double radical cross coupling mechanism has been reported by Zhao and coworkers ${ }^{[43]}$ (Eq. 19). Deriva-

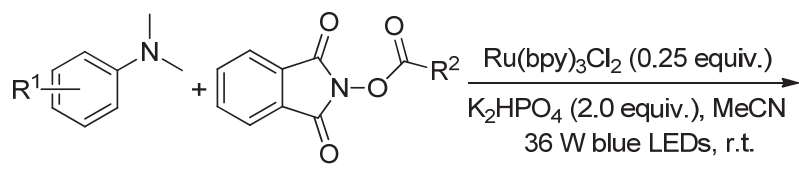

$\mathrm{R}^{1}=$ alkyl, halogen, $\mathrm{NO}_{2}, \mathrm{CN}, \mathrm{Ph} ; \mathrm{R}^{2}=$ alkyl, aryl<smiles>CN(CN1C(=O)c2ccccc2C1=O)c1c[R1]ccc1</smiles>

A metal-free KI-catalyzed imidation of $N, N$-dimethyl 
tives of $N$-acetyloxyphthalimide (RAEs) produce carboxylate ions and phthalimide free radicals in the photoredox cycle, and the latter can be free radical addition with aromatic rings to achieve direct amination of $\mathrm{C}\left(\mathrm{sp}^{2}\right)-\mathrm{H}$ bond.

In 2017, Prabhu and coworkers ${ }^{[44]}$ synthesized $\alpha$-aminophosphonates using CDC reaction of THIQs in the presence of open air without any catalyst and additional oxdiants. However, under their conditions, the reactions of nucleophiles including indole, 4-hydroxycoumarin and TBHP were unsuccessful (Eq. 20).

$\alpha$-Aminophosphonates could be synthesized by the use of cobalt-mediated oxidation of tertiary aliphatic amines. Tang and coworkers ${ }^{[45]}$ developed this $\mathrm{C}-\mathrm{P}$ bond forming process recently (Scheme 21). They also explored the $N$-aryl tetrahydroisoquinoline substrates in this reaction and some of them gave the desired products in quantitative yields. At the first stage, the authors proposed that a complex 55 was formed from NHPI and $\mathrm{Co}(\mathrm{OAc})_{2}$. $\mathrm{Co}$ (III)-phthalimide- $N$-oxyl (PINO) radical 56 and $\mathrm{HOO}^{-}$ were produced by the deprotonation of $\mathbf{5 5}$ in the presence of oxygen. Subsequent coordination of Lewis basic tertiary amine with metal-complex 56 led to complex 57, which further gave aminyl radical $\mathbf{5 8}$ through intramolecular single electron transfer. The key intermediate iminium ion 59 could be generated from complex 58. The final product $\mathbf{6 0}$ was formed from phosphorus and iminium ion $\mathbf{5 9}$ by addition.

\subsection{Methylene donors}

The 1,3-dicarbonyl compounds are readily available building blocks in organic synthesis. In 2009, a methylene-bridged bis-1,3-dicarbonyl derivatives were efficiently constructed by an iron-catalyzed reaction of 1,3-dicarbonyl compounds and $N, N$-dimethylaniline in the presence of ${ }^{t} \mathrm{BuOOH}$, in which the methyl group of $N, N$-dimethylaniline acted as the methylene source. ${ }^{[46]}$ The trialkyl amines including $N, N$-dimethylbenzyl amine and $N$-methyl pyrrolidine were also studied and were proved to be not optimal. After investigation of the mechanism, the authors proposed a tandem Cope elimination and Michael addition pathway, and compound $\mathbf{6 1}$ was regarded as a key intermediate (Scheme 22).

Three years after this discovery, a similar synthesis of methylene-bridged bis-1,3-dicarbonyl derivatives under visible-light photocatalysis was developed by Kobayashi's group. ${ }^{[47]} N, N$-Dimethylbenzyl amine used in their method was found to be a better methylene donor (Eq. 21).

Our group ${ }^{[48]}$ focused on the metal-free method for the synthesis of bis-1,3-carbonyl compounds and found that $\mathrm{N}, \mathrm{N}$-diisopropylethylamine (DIPEA) was a good methylene donor under tetrabutylammonium iodide (TBAI)catalyzed conditions (Eq. 22).

Interestingly, the $\beta$-carbon of DIPEA was converted to the methylene carbon through an oxidative $\mathrm{C}-\mathrm{C}$ bond cleavage. The result was verified by a ${ }^{13} \mathrm{C}$-labeled experiment. We further disclosed a mild and efficient cascade synthesis of 1,5-diketones by using a three-component reaction of $N, N$-dicyclohexylmethylamine, 1,3-dicarbonyl compounds and trifluoromethyl $\beta$-diketones. The

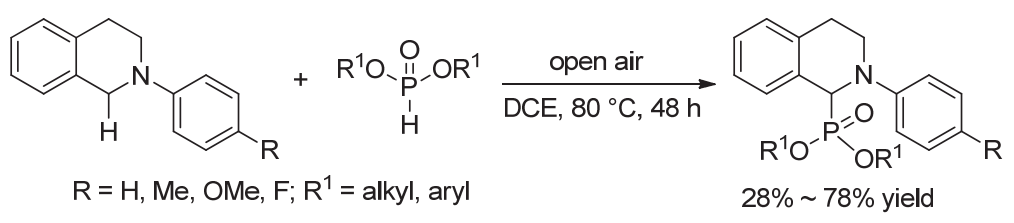
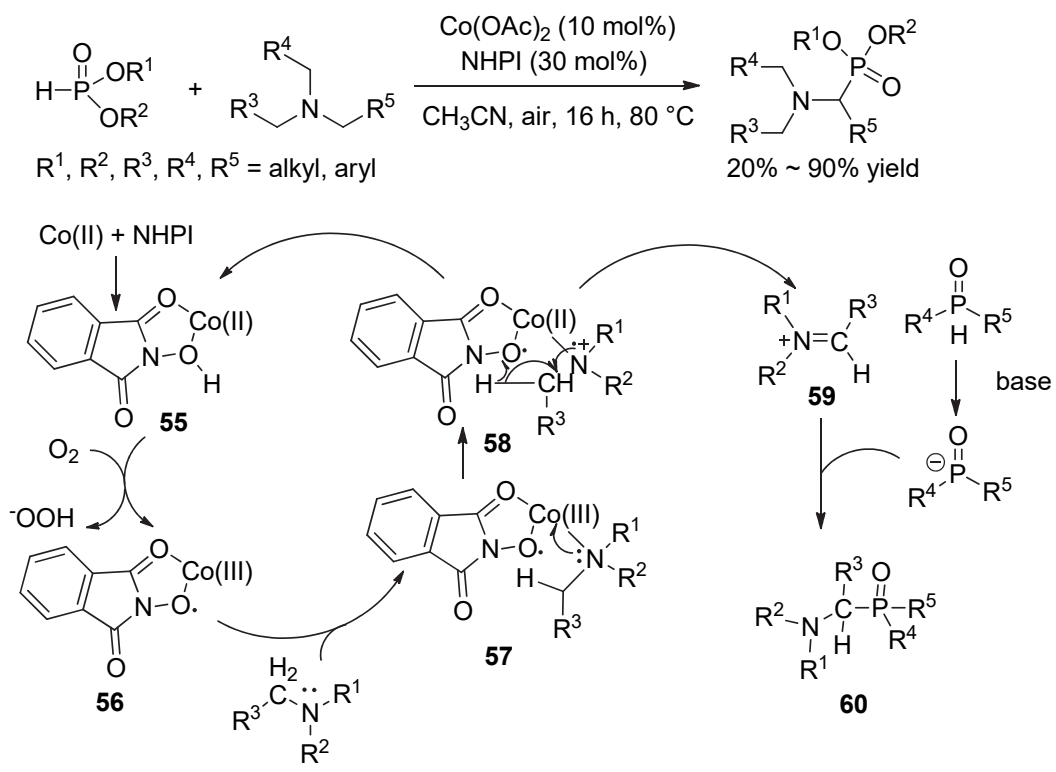

Scheme 21 Synthesis of $\alpha$-aminophosphonates 


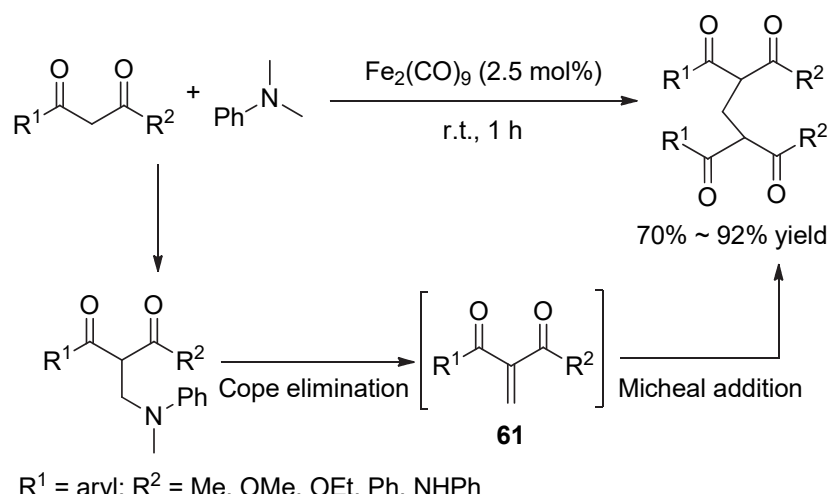

$\mathrm{R}^{1}=\operatorname{aryl} ; \mathrm{R}^{2}=\mathrm{Me}, \mathrm{OMe}, \mathrm{OEt}, \mathrm{Ph}, \mathrm{NHPh}$

Scheme 22 Synthesis of the methylene-bridged bis-1,3dicarbonyl derivatives

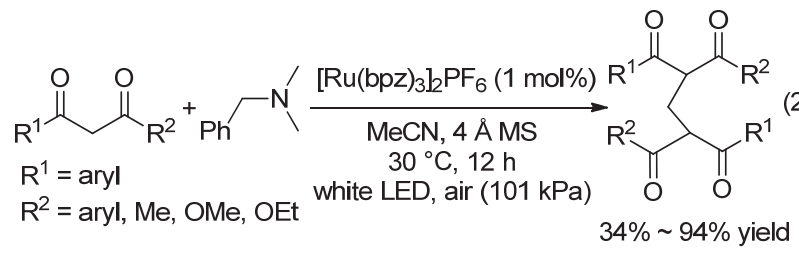

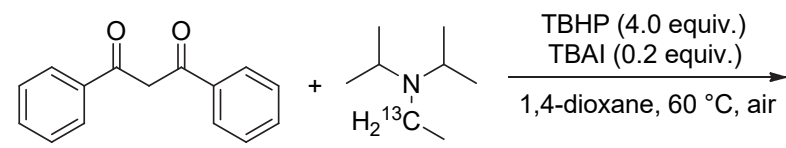

$$
{ }^{13} \mathrm{C} \text {-abundance, } 1.8 \%
$$

catalyst-free reaction occurred through an oxidation/Mannich reaction/Cope elimination/Michael addition/retro-Claisen reaction sequence, and provided multiple $\mathrm{C}-\mathrm{C}$ bond formations in one pot (Eq. 23). ${ }^{[49]} \mathrm{Cai}$ and coworkers $^{[50]}$ developed a method for the preparation of methylene-bridged bis-1,3-dicarbonyl compounds. In their reaction, tetramethylethylenediamine (TMEDA) was used as the methylene source, and cuprous iodide as catalyst under aerobic condition (Eq. 24).

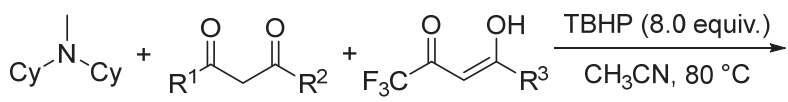

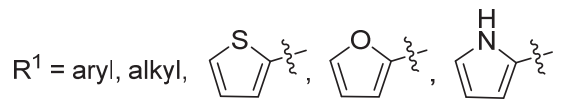

$$
\begin{aligned}
& \mathrm{R}^{2}=\mathrm{OMe}, \mathrm{OEt}, \mathrm{O} i-\mathrm{Pr}, \mathrm{Ph} \\
& \mathrm{R}^{3}=\mathrm{Me}, \text { aryl, }
\end{aligned}
$$

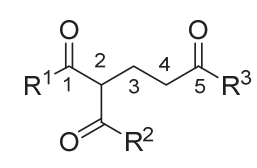

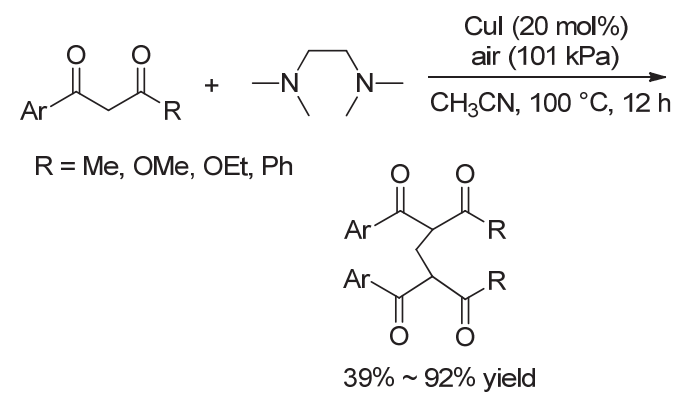

\subsection{Imine donors}

In 2015, Zheng and coworkers ${ }^{[51]}$ disclosed a NaIpromoted detetrahydrogenative cross-coupling reaction of $\mathrm{N}, \mathrm{N}$-dimethyl aniline with sulfonamide to prepare sulfonyl amidine derivatives without using transition-metal (Eq. 25). A radical pathway similar to Scheme 4 was proposed by authors. The resulting imine motif was remained rather than hydrolyzed under the conditions.

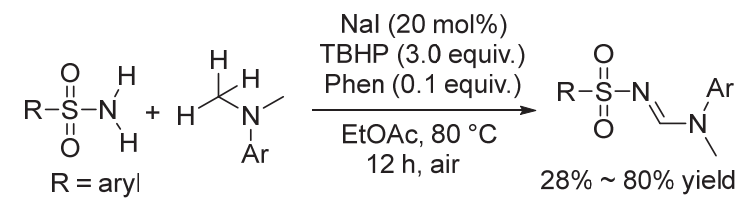

Tilve and coworkers ${ }^{[52]}$ developed an $\mathrm{I}_{2}$-catalyzed intramolecular dehydrogenative coupling reaction, which could be used for the synthesis of isocryptolepine in salt form. The authors suggested that the reaction occurred through a (hypo)iodite-mediated pathway rather than a radical pathway (Scheme 23). After investigation of the reaction in the presence of (2,2,6,6-tetramethylpiperidin1-yl)oxyl (TEMPO) or butylated hydroxytoluene (BHT), they excluded the radical mechanism and proposed a hypoiodite-mediated pathway, which was different from the work of Zheng's group. ${ }^{[51]}$ Molecular iodine and substrate formed a tertiary amine salt $\mathbf{6 2}$, which was then oxidized by TBHP to produce $\mathrm{IO}^{-}$. The key intermediate iminium ion 64 was generated via the deprotonation of 63 . The intramolecular cyclization and elimination of HI gave intermediate 65 , which produced the final product 66 via a similar process from 62 to 64 .

\subsection{Miscellaneous roles}

A method for the formation of isatoic anhydride using palladium as the catalyst via multistep tandem reaction was reported by Ji and Jiang's group ${ }^{[53]}$ (Eq. 26). The demethylation of $N, N$-dimethylaniline occurred and carbon monoxide served as carbonyl source. The authors proposed that the intermediate of the reaction was 2-(dimethylamino)benzoic acid rather than 1-methylindoline-2,3-dione.

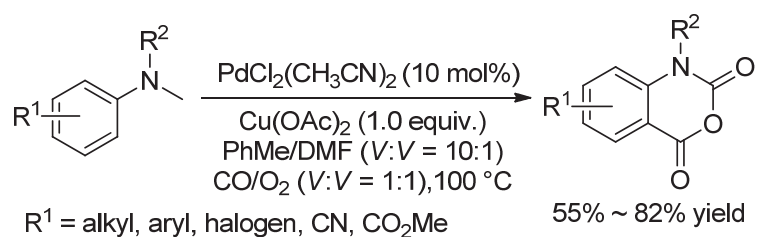


<smiles>CN(C)c1ccccc1-c1cc2ccccc2n1C</smiles><smiles>CN(C)c1ccccc1-c1cn(C)c2ccccc12</smiles>
$\mathrm{I}_{2}(1.1$ equiv. $)$ $\underset{\mathrm{CHCl}_{3} \text {, r.t. }}{\stackrel{\operatorname{TBHP}(2.0 \text { equiv. })}{\longrightarrow}}$<smiles></smiles>
$75 \%$ yield<smiles></smiles>
$53 \%$ yield<smiles>CN(C)c1ccccc1-c1cc2ccccc2n1C</smiles><smiles>Cn1c(-c2ccccc2[N+](C)(C)I)cc2ccccc21</smiles>

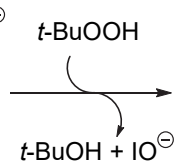<smiles>CN(C)c1ccccc1-c1cc2ccccc2n1C</smiles>

63<smiles></smiles>

${ }_{1}^{\ominus} \mathrm{CH}_{3}$<smiles>CCC1c2c(n(C)c3ccccc23)CN1C</smiles>

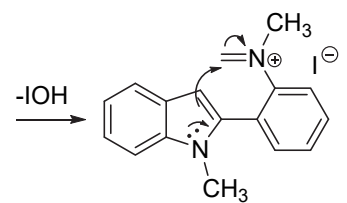

64

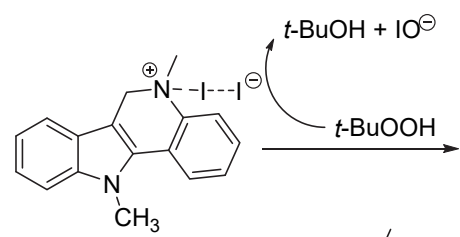<smiles></smiles><smiles></smiles>

66

Scheme 23 Intramolecular dehydrogenative coupling reaction

In 2010, Loh and coworkers ${ }^{[54]}$ described a novel tertiary amines rearrangement reaction for the direct synthesis of synthetically useful $\alpha$-amino acetals through the oxidation of aliphatic $\mathrm{C}-\mathrm{H}$ bonds with a dioxygen-copper catalytic system (Eq. 27). In comparison with the traditional methods for $\mathrm{C}-\mathrm{H}$ bond oxidation, this catalytic system has the clear advantages of mild reaction conditions and the use of air or oxygen as the oxidant.

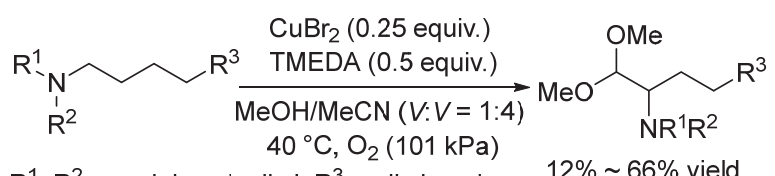

Huang and coworkers ${ }^{[55]}$ reported that rearrangement of propargylic amines was catalyzed by $\mathrm{Cu}(\mathrm{OAc})_{2} \bullet \mathrm{H}_{2} \mathrm{O}$ and $\mathrm{FeCl}_{3}$ through $\mathrm{C}-\mathrm{N}$ bond cleavage and $\mathrm{N}$-aryl group migration. Based on the ${ }^{18} \mathrm{O}$-labeling experiments, the authors suggested that the oxygen source in the reaction was from added $\mathrm{H}_{2} \mathrm{O}^{18}$ or the acid or $\mathrm{Cu}(\mathrm{OAc})_{2} \cdot \mathrm{H}_{2} \mathrm{O}$. The reaction gives good $E$-isomeric selectivity (Scheme 24$)$.

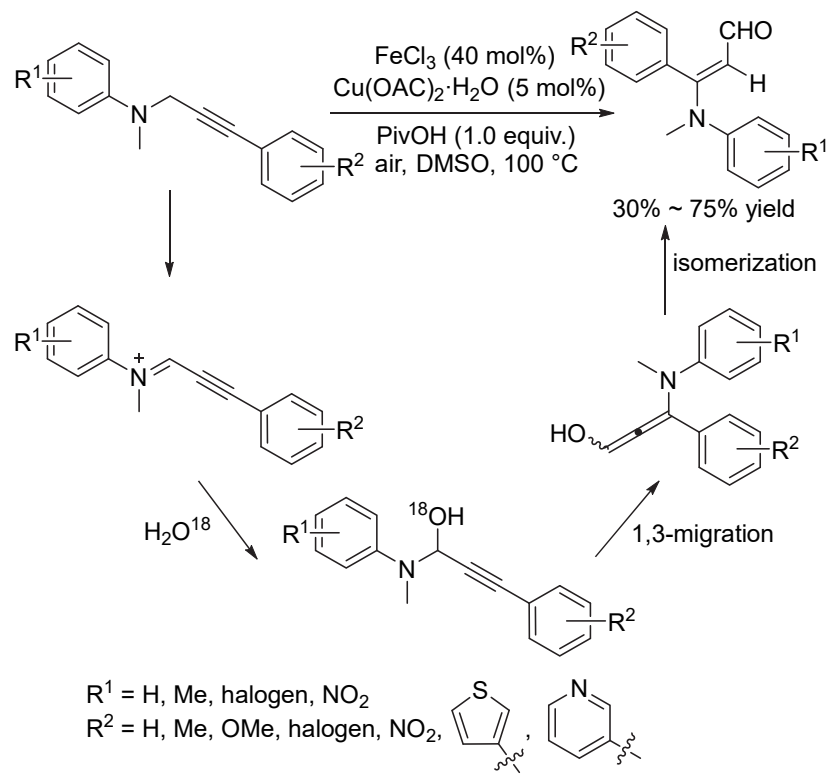

Scheme 24 Rearrangement of propargylic amines

By the use of a combination of $\mathrm{Cu}(\mathrm{I})$ and TBHP, Patel and coworkers ${ }^{[56]}$ reported an effective synthesis of 3 -aroylindoles from $O$-alkynylated $N, N$-dimethylamines (Scheme 25). This reaction underwent a $\mathrm{C}\left(\mathrm{sp}^{3}\right)-\mathrm{H}$ bond activation adjacent to the nitrogen atom, which was followed by an intramolecular nucleophilic attack with the

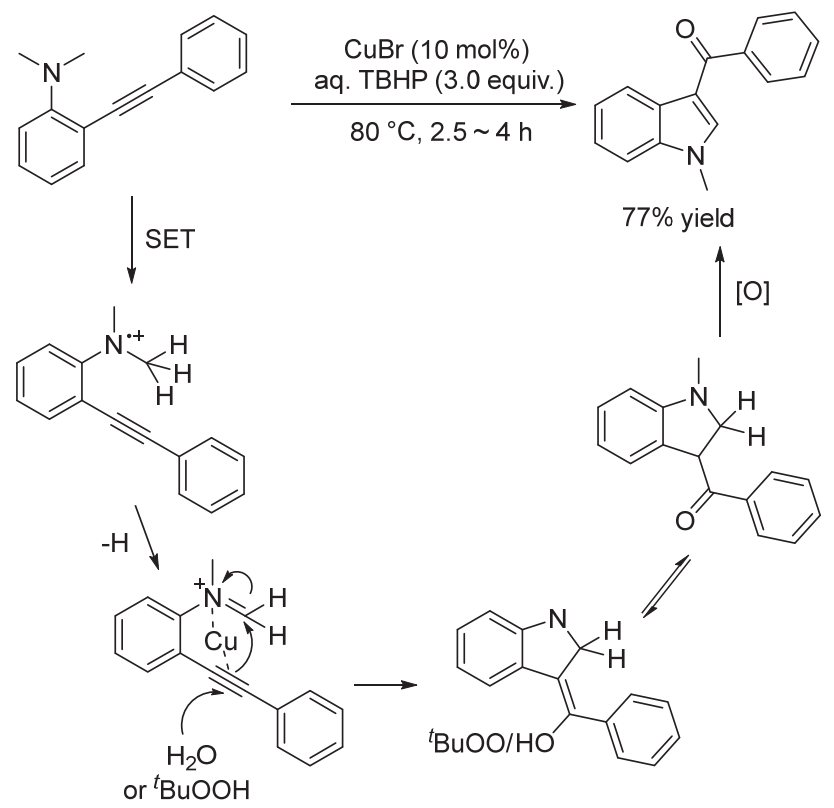

Scheme 25 Intramolecular cyclization for synthesis of acylated indoles 
alkyne. And eventually it forms new $\mathrm{C}-\mathrm{C}$ and $\mathrm{C}-\mathrm{O}$ bonds. TBHP acts not only as an oxidant but also as a radical initiator for this transformation.

Recently, Chandrasekhar and coworkers ${ }^{[57]}$ reported a similar method using sodium persulfate as oxidant for the synthesis of 3-aroylindoles through intramolecular oxidative cyclization in the absence of copper catalyst. The product was further used as a starting martial for the synthesis of food and drug administration (FDA)-approved anti-asthma drug zafirlukast (Scheme 26).

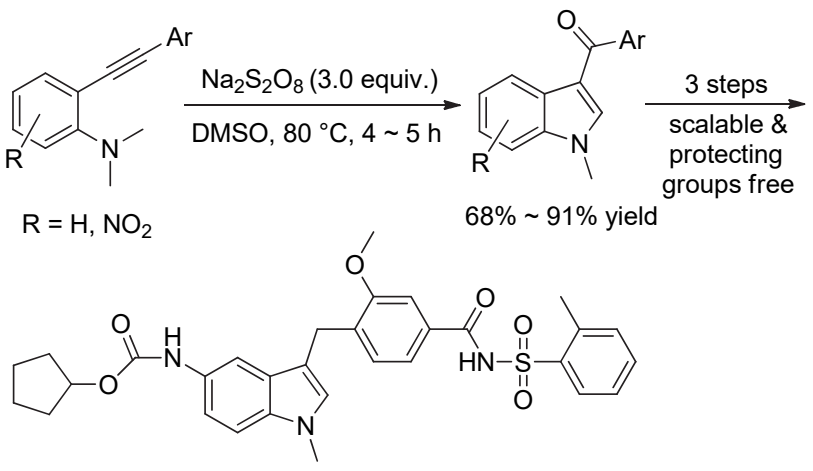

Zafirlukast

(anti-asthma drug) 28\% overall yield

Scheme 26 Synthesis of 3-aroylindoles

Soon after Patel's discovery, an intermolecular cyclization for the synthesis of indoles was reported by $\mathrm{Li}$ and Wang's group. ${ }^{[58]}$ In this work, $N, N$-dimethyl aniline $\mathrm{N}$-oxide and internal alkyne were used as the substrates and rhodium as a catalyst (Eq. 28).

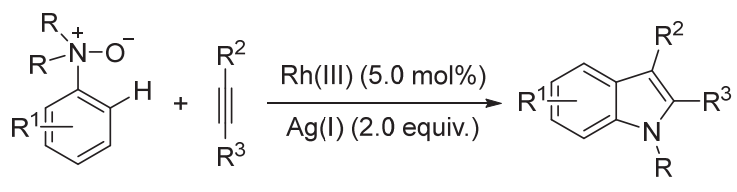

$\mathrm{R}=$ alkyl; $\mathrm{R}^{1}=$ alkyl, halogen;

$40 \% \sim 95 \%$ yield

$R^{2}, R^{3}=$ aryl, alkyl, $\left.\llbracket S^{S}\right\rangle-$

In 2014, Long and coworkers ${ }^{[59]}$ reported that TEMPO could promote oxidative amination to give multisubstituted benzimidazoles under metal-free conditions (Scheme 27). In this reaction, oxygen atmosphere is necessary to promote the regeneration of TEMPO, shorten the reaction

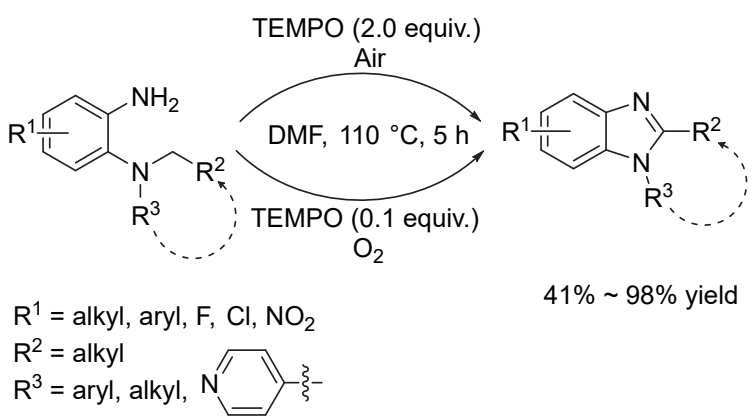

Scheme 27 Synthesis of multisubstituted benzimidazoles time and lower the reaction temperature. They proposed that an anilinium radical cation was formed by a SET pathway, which further underwent a hydrogen-transfer step and oxidation.

A three-component oxidative coupling reaction of $N, N$-dimethyl aniline, $\alpha$-diazo carbonyls and carboxylic acid (or $N$-methyl aniline) under convenient conditions was reported by Jiang and coworkers. ${ }^{[60]}$ The reaction proceeded via the formation of carbene, enolization and nucleophilic addition, resulting in the formation of $\alpha$-(acyloxy)$\beta$-amino ketones or $\alpha, \beta$-diamino ketones (Scheme 28).

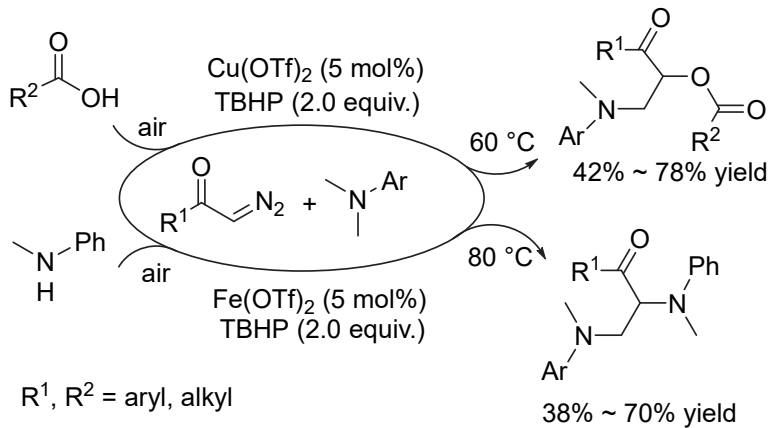

Scheme 28 Synthesis of $\alpha$-(acyloxy)- $\beta$-amino ketones or $\alpha, \beta$-diamino ketones

In 2018, Correa and coworkers ${ }^{[61]}$ developed an ironcatalyzed $\mathrm{C}\left(\mathrm{sp}^{3}\right)-\mathrm{H}$ oxidative Ugi-type reaction of $N, N$-dimethylanilines and isocyanides (Eq. 29). They proposed that an iminium ion intermediate was formed from $\mathrm{N}, \mathrm{N}$-dimethylanilines, which further underwent the nucleophilic attack of isocyanides. This one-pot protocol could be used for the assembly of $\alpha$-amino amides and short peptides. They also found the addition of carboxylic acids or picolinic acid could promote the synthesis of $\alpha$-amino imides through a three-component reaction.

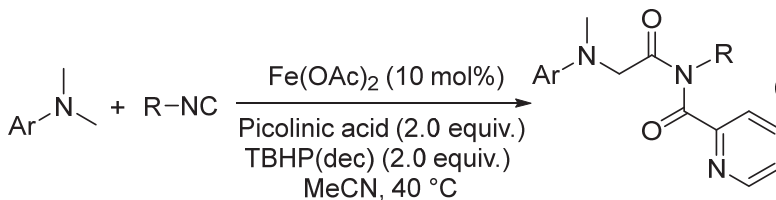

$$
\begin{aligned}
& \mathrm{R}=\mathrm{Cy},\left(\mathrm{CH}_{2}\right)_{4} \mathrm{CH}_{3} \text {, 终 } \mathrm{Ts} \text {, 经 } \underset{\mathrm{O}}{\mathrm{P}}(\mathrm{OEt})_{2} \\
& 49 \% \sim 64 \% \text { yield }
\end{aligned}
$$

In 2020, Constantin and coworkers ${ }^{[62]}$ reported that $\alpha$-aminoalkyl radicals as halogen-atom transfer (XAT) agents can convert alkyl and aryl halides to carbon radicals (Scheme 29). Simple amines are easy to produce this $\alpha$-aminoalkyl radicals through a SET process. These reagents promoting the homolytic activation of carbonhalogen bonds display a reactivity profile similar to that of tin radicals. This XAT strategy show cases the strong chemoselectivity under mild conditions for the engagement of unactivated alkyl and aryl halides in redox chemistry to construct $\mathrm{sp}^{3}-\mathrm{sp}^{3}, \mathrm{sp}^{3}-\mathrm{sp}^{2}$, and $\mathrm{sp}^{2}-\mathrm{sp}^{2}$ carbon-carbon bonds.

Recently, the visible-light induced $\mathrm{CDC}$ reaction at- 


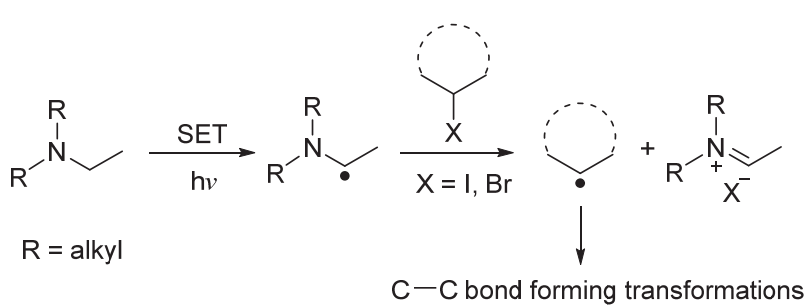

Scheme 29 Transformation using alkyl and aryl halides activated via $\alpha$-aminoalkyl radical-mediated XAT

tracted great interests due to its green features. Zhou and coworkers $^{[63]}$ reported the coupling reaction of THIQ with diazo compounds with $\mathrm{O}_{2}$ or air as oxidant under visiblelight induced conditions. A SET pathway was suggested by authors (Scheme 30). The excited species RB* was formed from visible light irradiation of Rose Bengal. Then intermediate 67 was generated through the SET process. The resulting $\mathrm{RB}^{--}$was then oxidized by $\mathrm{O}_{2}$ to afford a superoxide radical anion with concomitant regeneration of the photocatalyst. Then oxygen abstracted hydrogen atom to provide the iminium ion $\mathbf{6 8}$. The generally nucleophilic attack of a diazo compound produced intermediate 69. After deprotonation intermediate $\mathbf{6 9}$ gave the final product 70.
$\mathrm{Tu}$ and Jiang's group ${ }^{[64]}$ developed a three-component carbo-oxygenation of $\alpha$-diazo carbonyls for flexible synthesis of unprecedented $\alpha$-aminooxy- $\beta$-amino ketones. They suggested this metal-free $\mathrm{PhI}(\mathrm{OAc})_{2}$ oxidative reaction proceeded through free radical dediazotization (Eq. 30).
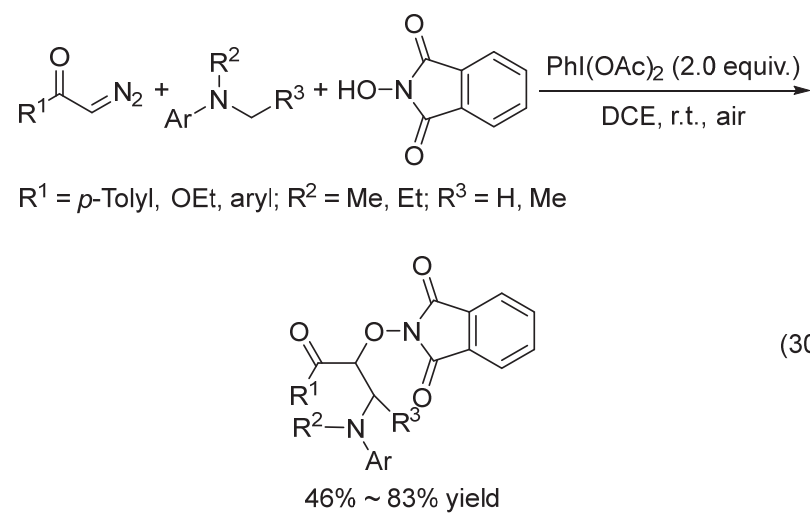

In 2019, this group ${ }^{[65]}$ further reported another reaction of THIQ with diazo compounds for preparing indolo[2,1$a$ ]isoquinolines. The reation proceeded through a $\mathrm{Cu}-$

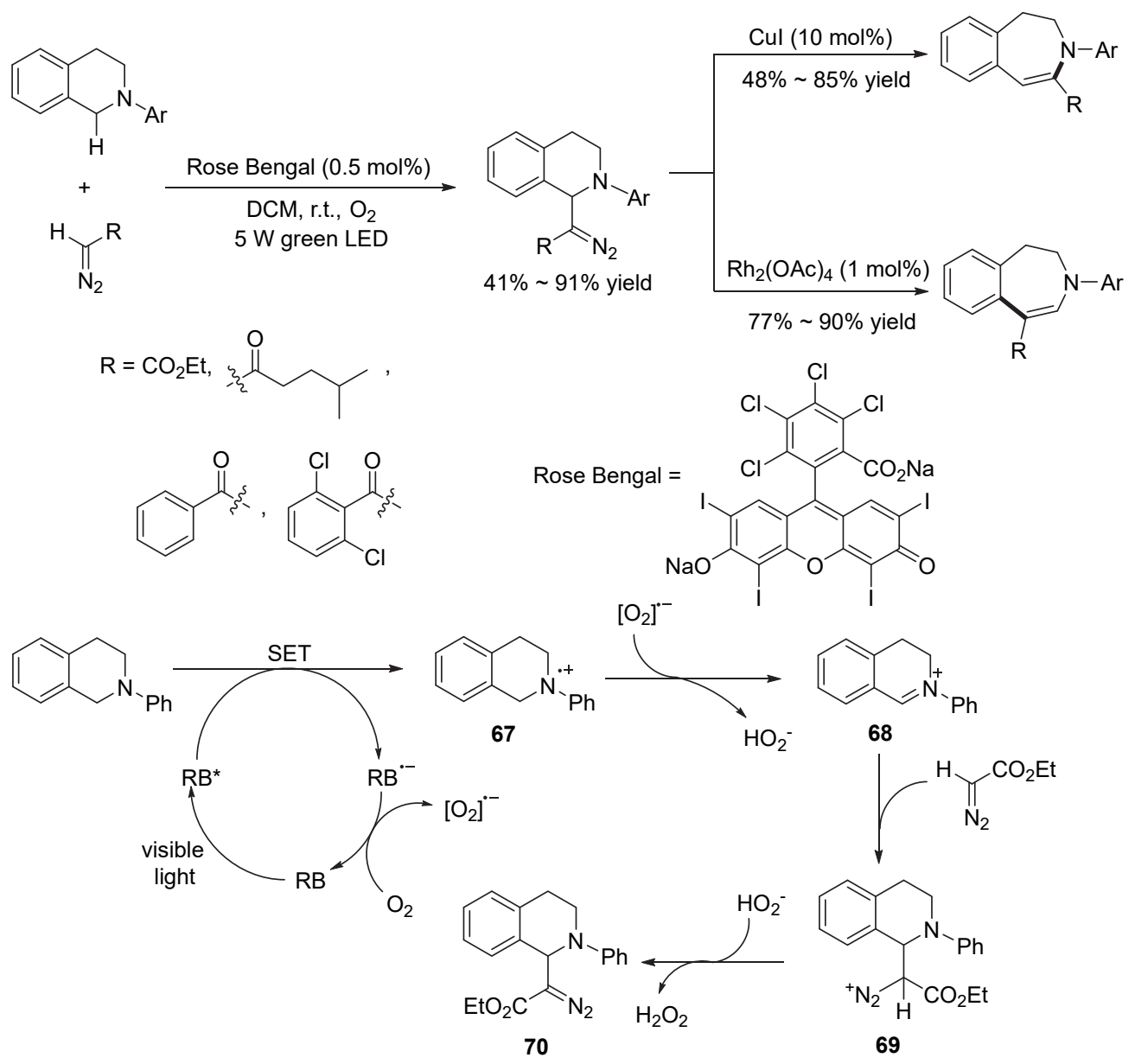

Scheme 30 Metal-free visible-light induced CDC of tertiary amines with diazo compounds 
catalyzed $[4+1]$ annulation with TBHP as oxidant in the presence of $\mathrm{Na}_{2} \mathrm{CO}_{3}$ (Eq. 31).

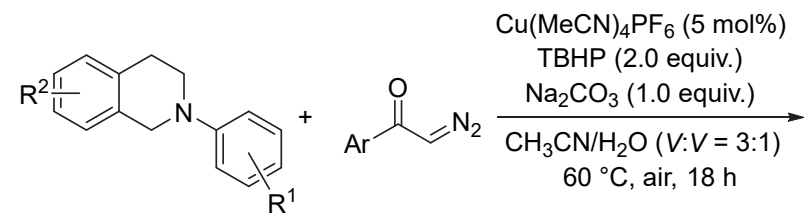

$\mathrm{R}^{1}=\mathrm{H}$, halogen, alkyl; $\mathrm{R}^{2}=\mathrm{H}, \mathrm{Br}$<smiles>[R]c1cccc2c1CCn1c-2c(C(=O)[Al])c2ccccc21</smiles>

Most of the CDC reactions of THIQ occurred at only one site, which was the $\alpha$ position of nitrogen. Wu's group $^{[66]}$ developed a useful cyclization reaction of $\mathrm{N}$-phenyl THIQ with crotonaldehyde where the $\mathrm{C}-\mathrm{H}$ bond of $N$-phenyl group participated in the reaction. This interesting metal-free catalyzed oxidative formal $[4+2]$ cycloaddition of $\mathrm{N}$-aryl tetrahydroisoquinolines with crotonaldehyde through tandem dienamine-iminium catalysis afforded a variety of ring-fused tetrahydroquinoline derivatives with good diastereoselectivities. After the study of the control experiment, the authors proposed the mecha- nism (Scheme 31). They suggested a key intermediate $\mathbf{7 3}$ was formed from 72-induced dienamine activation of crotonaldehyde $\mathbf{7 1}$. It then reacted with iminium intermediate 74 to afford intermediate $\mathbf{7 5}$. Intramolecular hydroarylation of 75 gave enamine 76. The finally hydrolysis of enamine 76 produced the product and regenerated amine catalyst.

\section{Reactions of secondary amines}

\subsection{Alkylation reagents}

Recently, Cai and coworkers ${ }^{[67]}$ developed an ironcatalyzed $\alpha-\mathrm{C}-\mathrm{H}$ alkylation of $N$-methylaniline with alkanes, cyclic ethers and toluene derivatives. These reaction partners also served as solvents in the transformation. The reaction occurred at high temperature $\left(140{ }^{\circ} \mathrm{C}\right)$ and a radical mechanism was proposed by the authors (Scheme 32 ).

\subsection{Amination reagents}

Mori and coworkers ${ }^{[68]}$ studied the oxidative amination reactions of benzothiazoleand $N$-methylaniline through the direct $\mathrm{C}-\mathrm{H}$ and $\mathrm{N}-\mathrm{H}$ coupling. The reactions were carried out with sodium acetate and $20 \mathrm{~mol} \% \mathrm{Cu}(\mathrm{OAc})_{2}$ in xylene under oxygen atmosphere affording the product in $81 \%$ yield (Eq. 32). The high temperature and long reaction time were needed.

Malapaka's group ${ }^{[69]}$ reported a copper-catalyzed amidation/imidation of $\mathrm{N}$-arylglycine ester derivatives with a

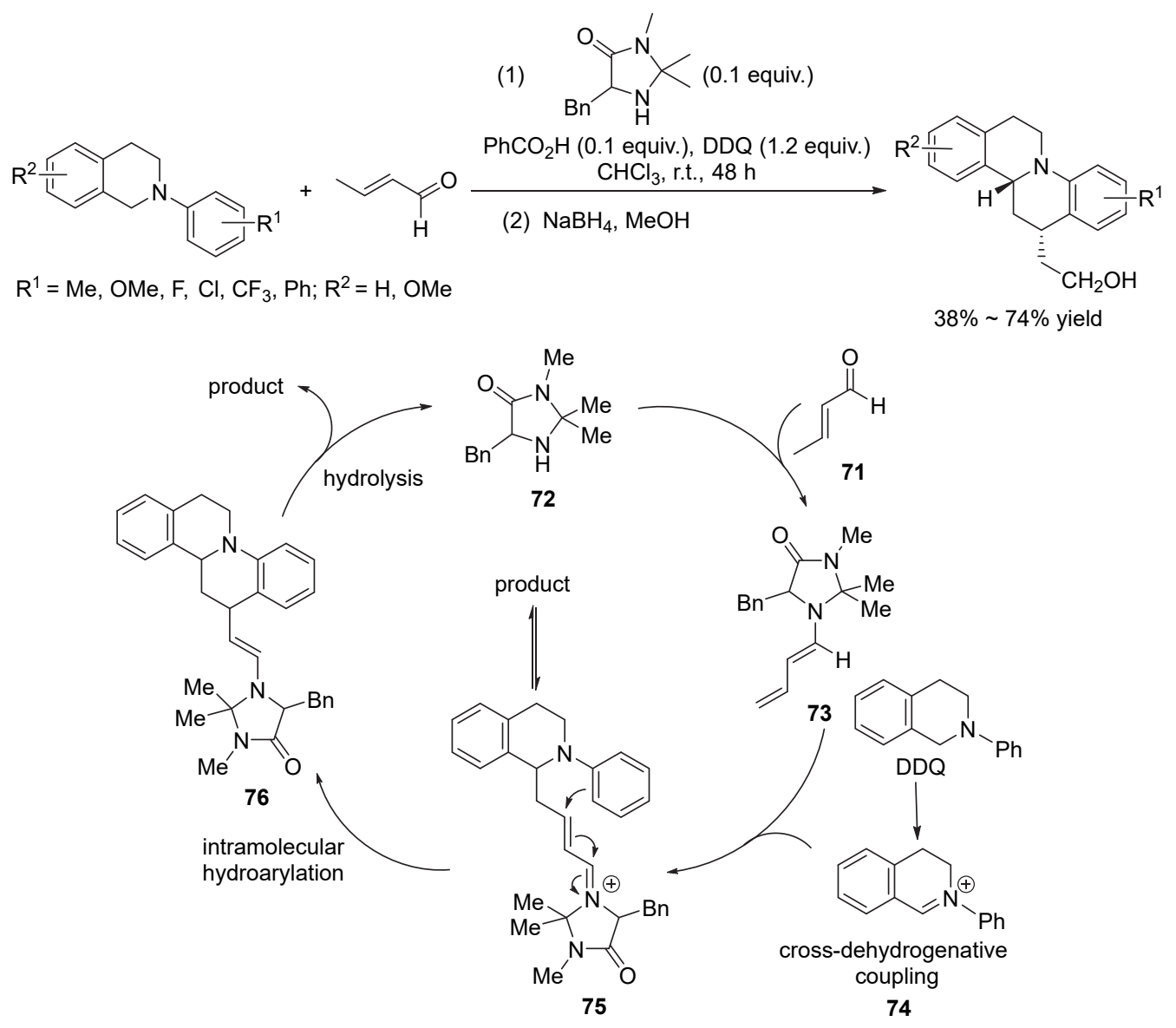

Scheme 31 [4+2] Cycloaddition of $N$-aryl tetrahydroisoquinolines with crotonaldehyde 


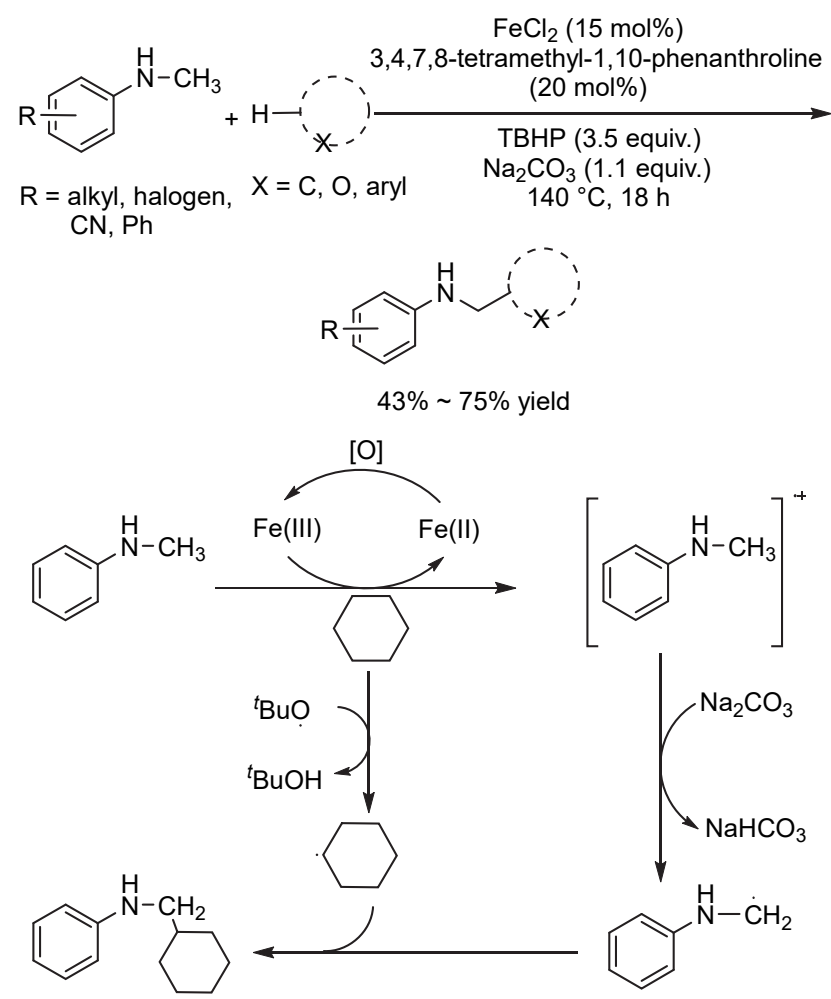

Scheme 32 Iron-catalyzed $\alpha-\mathrm{C}-\mathrm{H}$ alkylation of $N$-methylaniline

$$
\text { iy yield }
$$

variety of amide/imide/carbamates via dehydrogenative $\mathrm{C}\left(\mathrm{sp}^{3}\right)-\mathrm{N}$ cross-coupling under mild conditions (Scheme 33).

In the $\mathrm{CDC}$ reactions, the $\mathrm{CuBr}$ or $\mathrm{CuI}$ were frequently used, but the use of $\mathrm{CuSO}_{4}$ as a catalyst was seldom. Krishna and coworkers ${ }^{[70]}$ reported an interesting combination of $\mathrm{CuSO}_{4} / \mathrm{TBHP}$ used in the $\mathrm{CDC}$ reaction of $\mathrm{N}$-allylbenzamides with indole to prepare indole aminals (Scheme 34).

\subsection{Acylation reagents}

In 2011, $\mathrm{Wu}$ and $\mathrm{Su}^{[71]}$ studied the oxidative coupling reaction of $N$-methylaniline and indole, and they proposed that $N$-methylaniline formed an iminium ion intermediate under the catalytic oxidation of $\mathrm{RuCl}_{3}$ and TBHP. A nucleophilic addition of indole-C(3) to this intermediate afforded a secondary amine, which further underwent oxidation and hydrolysis to form the final indole acylated product (Scheme 35). They performed ${ }^{13} \mathrm{C}$-labeling experiments and verified that the carbonyl carbon atom of formylated product derived from methyl group of $N$-methylaniline. However, this method was not applicable to the $N$-substituted indoles and expensive $\mathrm{RuCl}_{3}$ was needed.

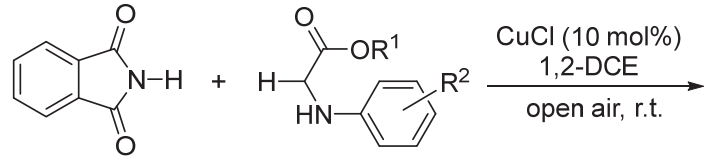

$\mathrm{R}^{1}=\mathrm{Me}, \mathrm{Et},{ }^{\mathrm{t}} \mathrm{Bu}, \mathrm{Bn} ; \mathrm{R}^{2}=\mathrm{H}, \mathrm{Me}, \mathrm{OMe}$, halogen<smiles>[R16]OC(=O)C(Nc1ccc([R])cc1)C(C(=O)O[R6])N1C(=O)c2ccccc2C1=O</smiles>

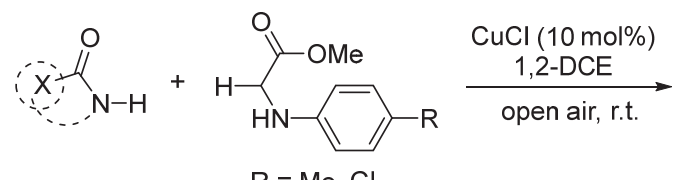

$\mathrm{R}=\mathrm{Me}, \mathrm{Cl}$<smiles>[R]c1ccc(NC(C(=O)OC)n2ncc3c2=C2C=3C2C)cc1</smiles>

$58 \% \sim 83 \%$ yield

Scheme $33 \mathrm{Cu}(\mathrm{I})$-catalyzed amidation/imidation of $N$-arylglycine ester derivatives

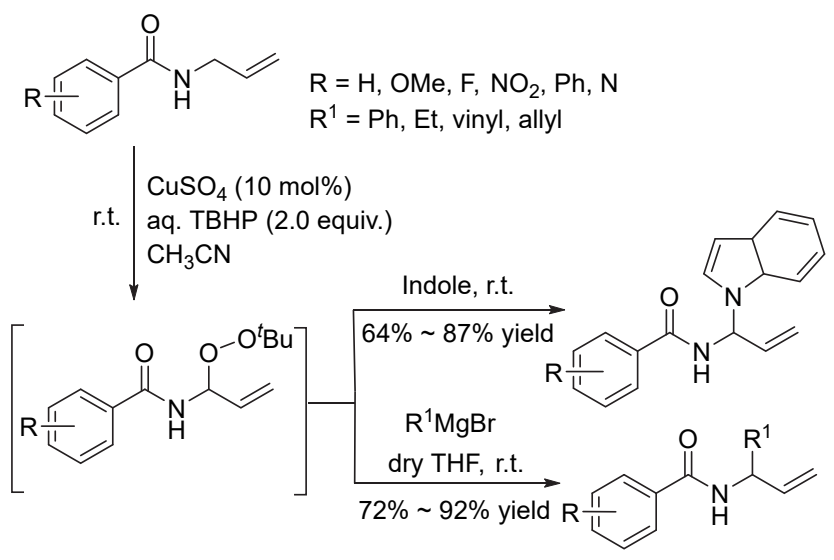

Scheme $34 \mathrm{C}-\mathrm{H}$ bond functionalization of allylbenzamides

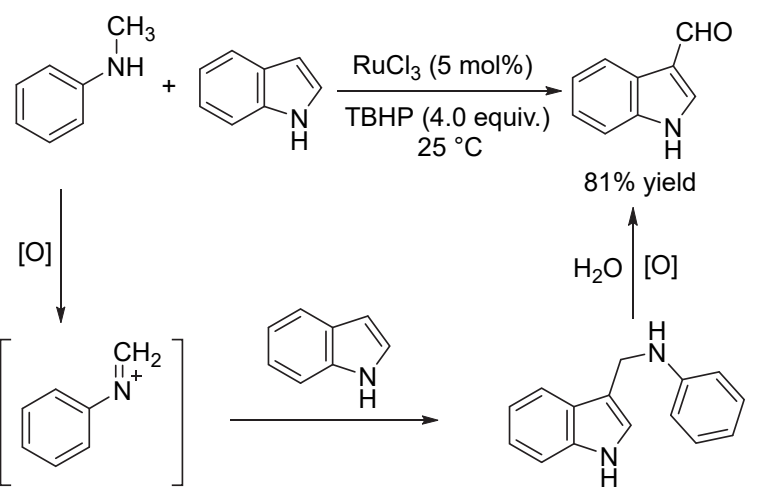

Scheme 35 Ru-catalyzed indole formylation

One year later, our group ${ }^{[72]}$ developed the $\mathrm{C}(3)$ selective formylation reaction of $\mathrm{N}-\mathrm{H}$ and $\mathrm{N}$-substituted indoles using $N$-methylaniline as a carbonyl source through 
a metal-free TBAI/TBHP catalysis (Scheme 36). Based on the control experiments, an iodine-mediated SET pathway was proposed. Initially, the reaction of iodide $\left(\mathrm{I}^{-}\right)$ion with TBPB through SET pathway provided a benzoyloxy radical (or tert-butyloxy radical) and iodine $\left(\mathrm{I}_{2}\right)$. The generated radical abstracted a hydrogen atom from the methyl group to afford radical 77 , followed by oxidation to afford the iminium ion 78. The nucleophilic attack of indole then occurred to afford intermediate 79, which underwent a similar process to give the second iminium ion $\mathbf{8 0}$, followed by hydrolysis to produce the final formylated product 81.

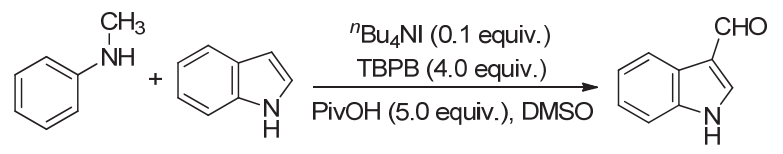

$82 \%$ yield

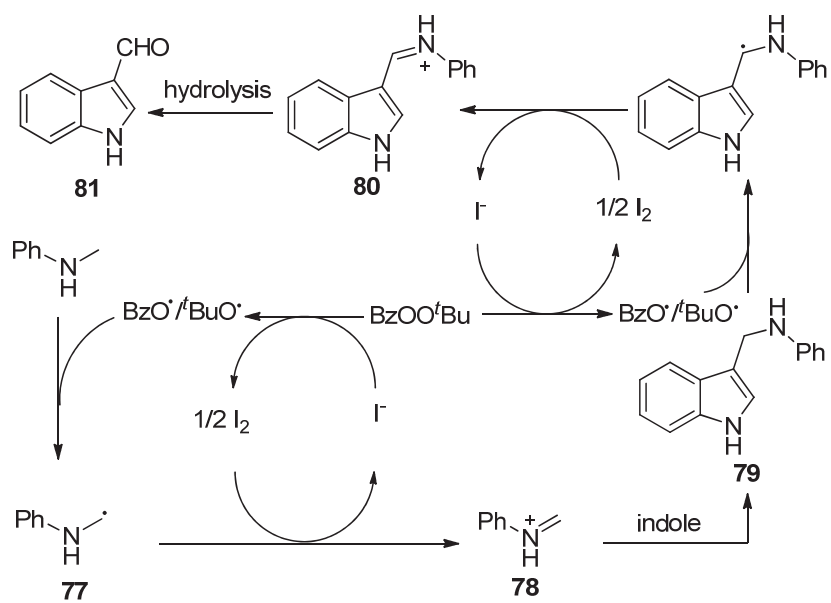

Scheme 36 C(3)-formylation of indole

Very recently, we ${ }^{[73]}$ reported a cyclization reaction of $N$-methyl aniline and tryptophan derivatives using TBAB/ TBHP catalysis system. After investigation of catalyst, we found that bromide was better than iodine in this cyclization. The valuable $\beta$-carbolines could be constructed by this metal-free method (Eq. 33).

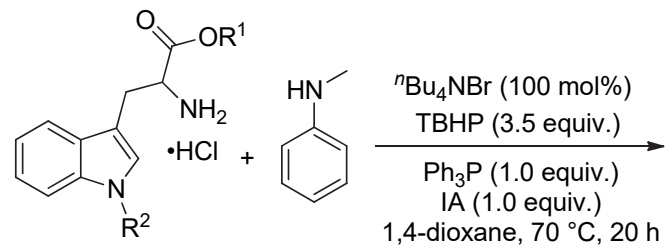

$\mathrm{R}^{1}=\mathrm{Me}, \mathrm{Et}, \mathrm{Bn} ; \mathrm{R}^{2}=\mathrm{H}, \mathrm{Me}, \mathrm{Bn}$, allyl

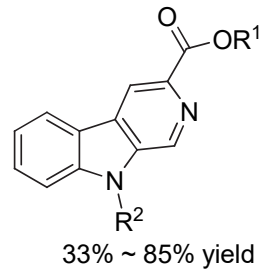

\subsection{Imine donors}

In 2012, Kanai and coworkers ${ }^{[74]}$ reported a useful cata- lytic aerobic oxidation of amines to imines using the combination of a sterically less-demanding and electrondeficient $N$-oxyl radical and copper salt. This method allowed for extension to a direct $\alpha$-derivatization of secondary amines via sequential aerobic amine oxidation to imines followed by $\mathrm{C}-\mathrm{C}$ bond formation to the resulting imines, including a catalytic asymmetric variant (Scheme 37 ).

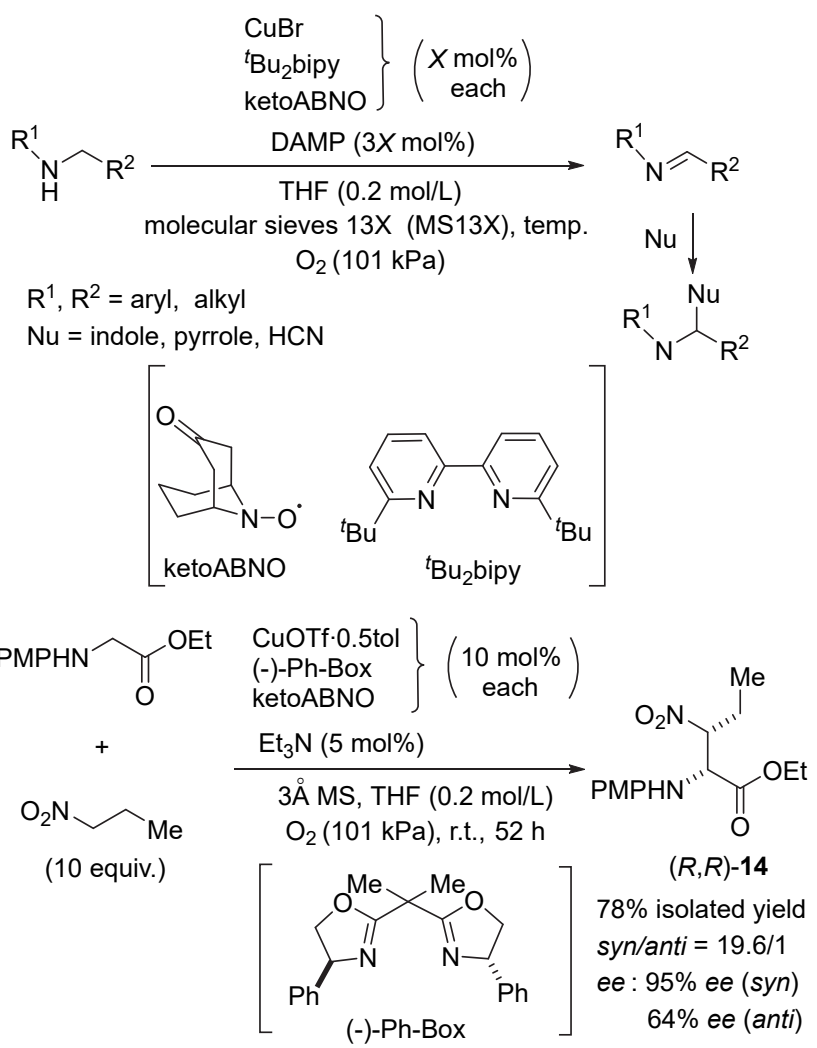

Scheme 37 Synthesis of imines from secondary amines

\section{Reactions of primary amines}

\subsection{Imine donors}

Many primary amines were utilized in the construction of heterocycles under oxidative conditions. The nitrogen atom and $\alpha$-carbon were simultaneously fused to the heterocycles such as oxazole, thiazoles, quinazolinone, imidazole, benzazole and 1,2,4-triazole. Primary amines provided the source of imine moiety in the synthesis of these $N$-heterocycles.

In 2010, benzylamine has been successfully utilized for the copper-catalyzed oxidative cyclization of $\beta$-diketone derivatives for the synthesis of polysubstituted oxazoles (Eq. 34). ${ }^{[75]} \mathrm{I}_{2}$ and $\mathrm{Cu}(\mathrm{OAc})_{2}$ were simultaneously used in the reaction, and the $\mathrm{I}_{2}$ was regarded as an additive, copper as a catalyst. In their mechanism exploration, the iodination of $\beta$-diketone was proposed as a key pathway. Recently, Yang and coworkers ${ }^{[76]}$ disclosed that $N$-iodosuccininide (NIS)/TBHP system was also effective for this transformation (Eq. 35). The use of copper catalyst was avoided. 


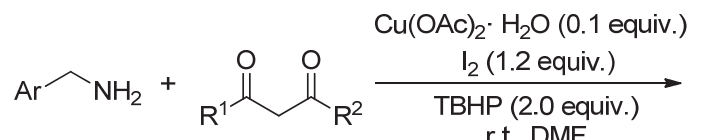

$$
\begin{aligned}
& \mathrm{R}^{1}, \mathrm{R}^{2}=\text { alkyl, aryl } \\
& \text { (18\% } \sim 91 \% \text { yield }
\end{aligned}
$$

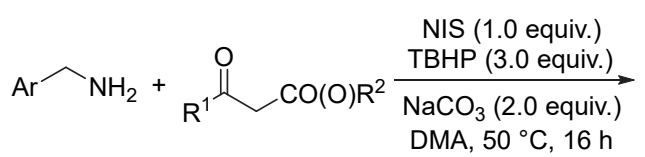

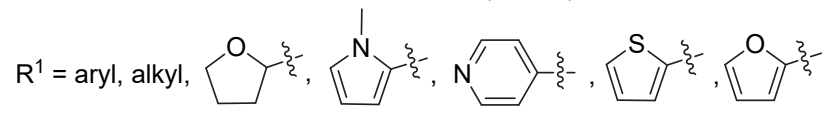

$$
\begin{aligned}
& \mathrm{R}^{2}=\mathrm{Et}, \mathrm{Me} \\
& \text { CO(O) R } R^{2}
\end{aligned}
$$

In addition to 1,3-dicarbonyl derivatives, alkenes and hydrazones were explored in the cyclization with primary amines. By using the combination of $\mathrm{I}_{2}$ and TBHP, a cyclization reaction has been applied to the synthesis of oxazoles from benzylamines and aryl alkenes (Scheme 38). ${ }^{[7]}$ The oxidation and iodination of styrene led to intermediate 82, which converted to intermediate $\mathbf{8 3}$ by Kornblum oxidation. The addition of benzylamine and intramolecular nucleophilic addition gave 84. Further oxidation by TBHP produced the final product $\mathbf{8 5}$. This catalyst system was subsequently applied in the cyclization of primary amines and hydrazones by Ren's group ${ }^{[78]}$ (Eq. 36). 1,3,5-Trisubstituted 1,2,4-triazoles were formed by the metal-free method.

$$
\text { }
$$

Scheme 38 Synthesis of oxazoles from benzylamines and aryl alkenes

$$
\mathrm{R}^{2}=\text { aryl, alkyl; } \mathrm{R}^{3}=\text { aryl, alkyl, }
$$

Recently, a $\mathrm{CO}_{2}$ /photoredox-cocatalyzed tandem oxidative cyclization of $\alpha$-bromo ketones and benzylamines for the synthesis of substituted oxazoles was developed (Eq. $37) \cdot{ }^{[79]}$

$$
\mathrm{R}=\text { aryl, alkyl, }
$$

2-Methyl $a z a$-heteroarenes have a reactivity similar to $\beta$-diketones or $\beta$-ketoesters. In 2013, Wang and cowork$\operatorname{ers}^{[80]}$ developed a NIS-mediated oxidative amination of benzylamine and ethyl 2-(pyridin-2-yl)acetate for the synthesis of imidazo[1,5-a]pyridines (Scheme 39). They proposed a free radical rather than iodination pathway at the beginning of the reaction. The nucleophilic substitution of amine to $\mathbf{8 6}$ produced an intermediate $\mathbf{8 7}$, which generated intermediate $\mathbf{8 8}$ via $\mathbf{8 9}$ oxidative dehydrogenation. The similar SET process and oxidation provided the final product 90. Two years later, a copper-catalyzed version was reported by Adimurthy's group. ${ }^{\left[{ }^{[1]}\right.}$ Air was used as the oxidant in their reaction (Eq. 38).

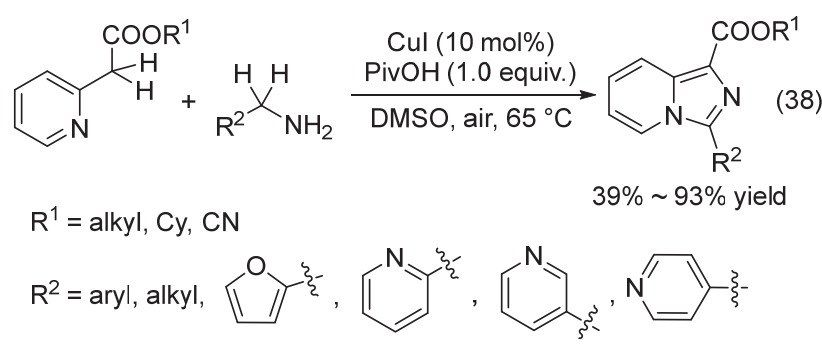

Recently, Wang's group further found that $\mathrm{NH}_{4} \mathrm{I}$ could also promote the cyclization of amines by anodic oxidation (Eqs. 39 ${ }^{[82]}$ and $40^{[83]}$ ). The additions of metal catalyst and external oxidant were avoided in this electrosynthesis of 1,3-disubstituted imidazo[1,5- $a]$ quinolines.

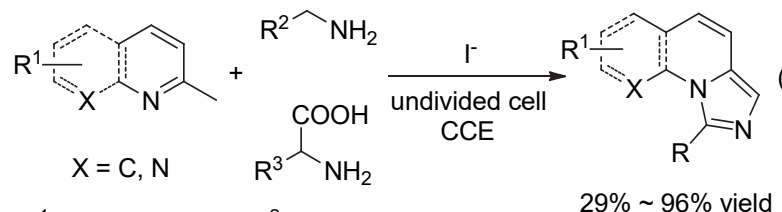

$\mathrm{R}^{1}=$ alkyl, halogen; $\mathrm{R}^{2}=$ aryl, thienyl, pryidyl;

$29 \% \sim 96 \%$ yield

$\mathrm{R}^{3}=$ alkyl, aryl; $\mathrm{R}=\mathrm{R}^{2}$ or $\mathrm{R}^{3}$ 


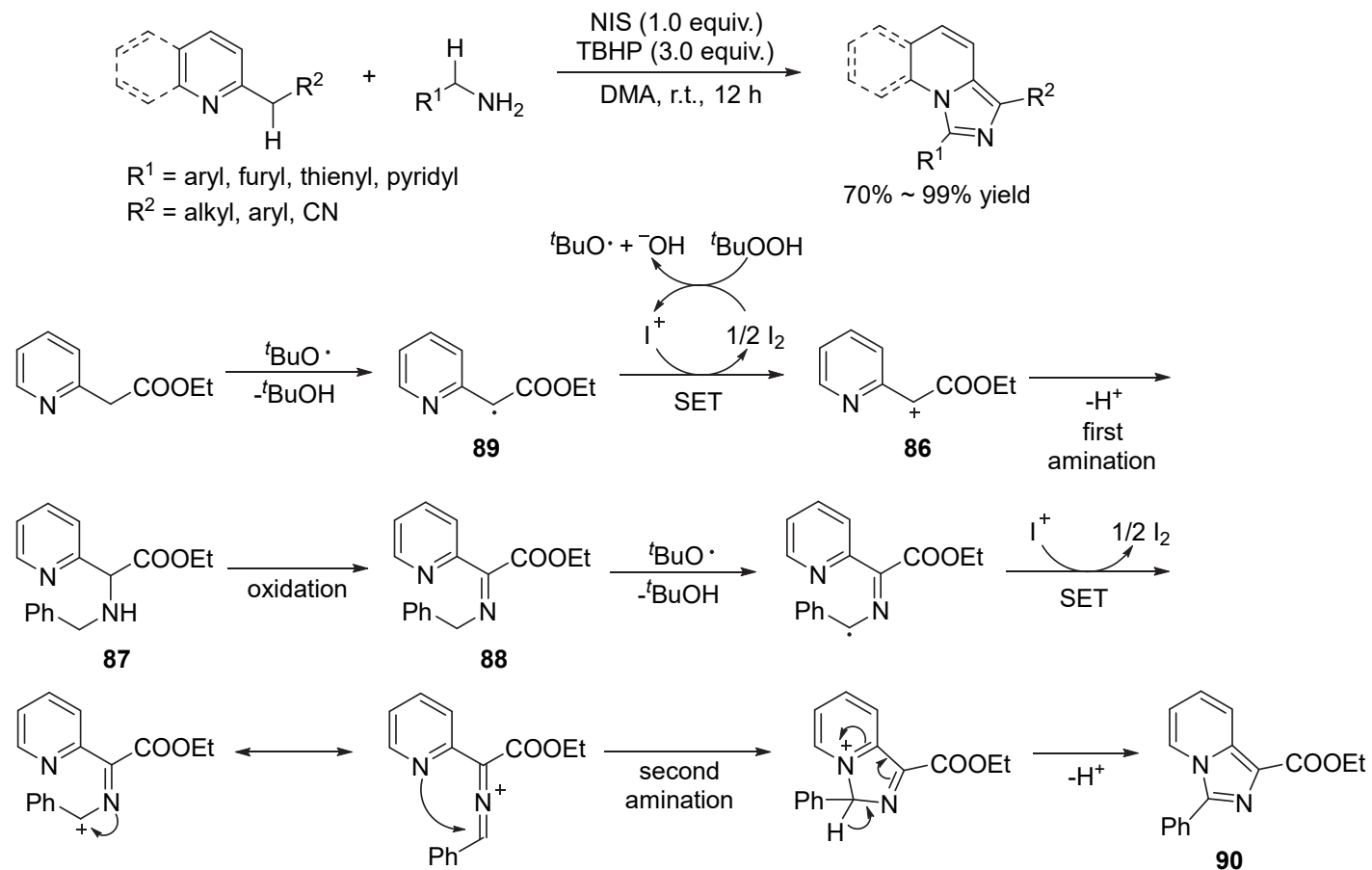

Scheme 39 Synthesis of imidazo[1,5-a]pyridines

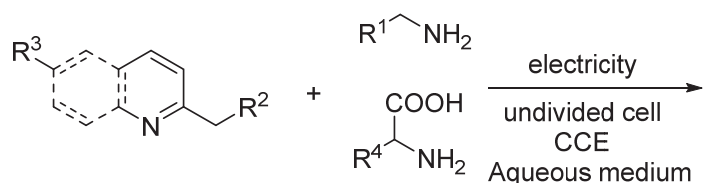

$\mathrm{R}^{1}=$ aryl, furyl, thienyl, pryidyl; $\mathrm{R}^{2}=$ COOEt, COOMe, COPh;

$\mathrm{R}^{3}=$ alkyl, halogen; $\mathrm{R}^{4}=$ aryl, alkyl; $\mathrm{R}=\mathrm{R}^{1}$ or $\mathrm{R}^{4}$<smiles>[R]c1ccc2c(ccc3c([R])nc([R])n32)c1</smiles>

In 2014, 2-formylpyridine was examined as a coupling partner in the reaction with benzylamine. The multifunctional imidazo[1,5-a]pyridines were successfully constructed under atmospheric oxygen through $\mathrm{CuBr}$ catalysis (Eq. 41). ${ }^{[84]}$ One year later, a similar reaction between pyridine ketone and benzylamine was developed for the synthesis of 1,3-diarylated imidazo[1,5-a]pyridines (Eq. 42). ${ }^{\left[{ }^{85]}\right.}$ Recently, the synthesis of imidazo-fused $N$-heterocycles from 2-methylazaarenes and benzylamines under copper-catalyzed conditions was achieved independently by Ma and Zhang's groups ${ }^{[86]}$ (Eq. 43 and Scheme 40).

By the use of primary amines, oxygen and different substrates, Jiao's group ${ }^{[87]}$ developed a copper-catalyzed aerobic dehydrogenative annulation for the synthesis of oxazoles. In 2012, they described the synthesis of oxazoles through a $\mathrm{Cu}$-mediated aerobic oxidative dehydrogenative annulation of primary amines, aldehydes and molecular oxygen (Scheme 41). Initially, an imine was formed from aldehydes 91 and anilines 92 through dehydrating. The

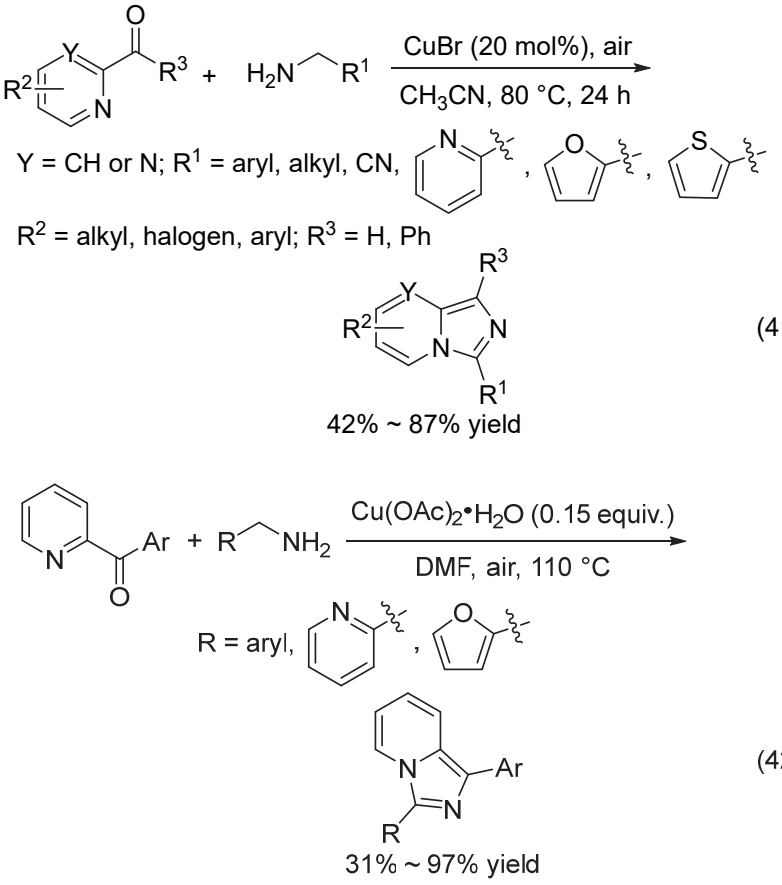

Cul (1.0 equiv.)

管 $\mathrm{R}^{1}=\mathrm{Me}, \mathrm{OMe}$, OEt, halogen, $\mathrm{NO}_{2}$

$\mathrm{R}^{2}=$ aryl, Et, $\llbracket \mathrm{S}^{\mathrm{S}}$ 

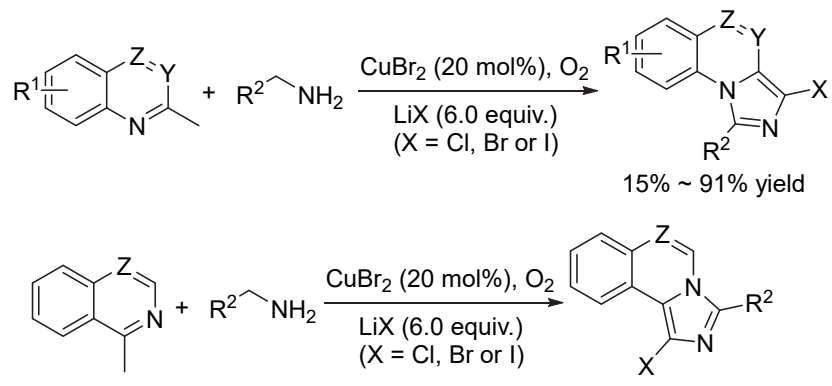

$\mathrm{Y}, \mathrm{Z}=\mathrm{CH}$ or $\mathrm{N} ; \mathrm{R}^{1}=\mathrm{H}, \mathrm{Me}, \mathrm{OMe}, \mathrm{Cl}, \mathrm{Br} ; \quad 70 \% \sim 72 \%$ yield $R^{2}=\operatorname{aryl}, \llbracket S \|^{-} \xi$

Scheme 40 Copper-promoted double oxidative C-H amination oxidation of imine by oxygen provided radical intermediate 93 in the presence of copper catalyst under basic conditions. Intermediate 94 was generated from 93 through the 1,5-hydrogen atom abstraction. Intramolecular free radical coupling afforded the 4,5-dihydrooxazole intermediate $\mathbf{9 5}$, which was oxidized by oxygen to the desired oxazole product 96.

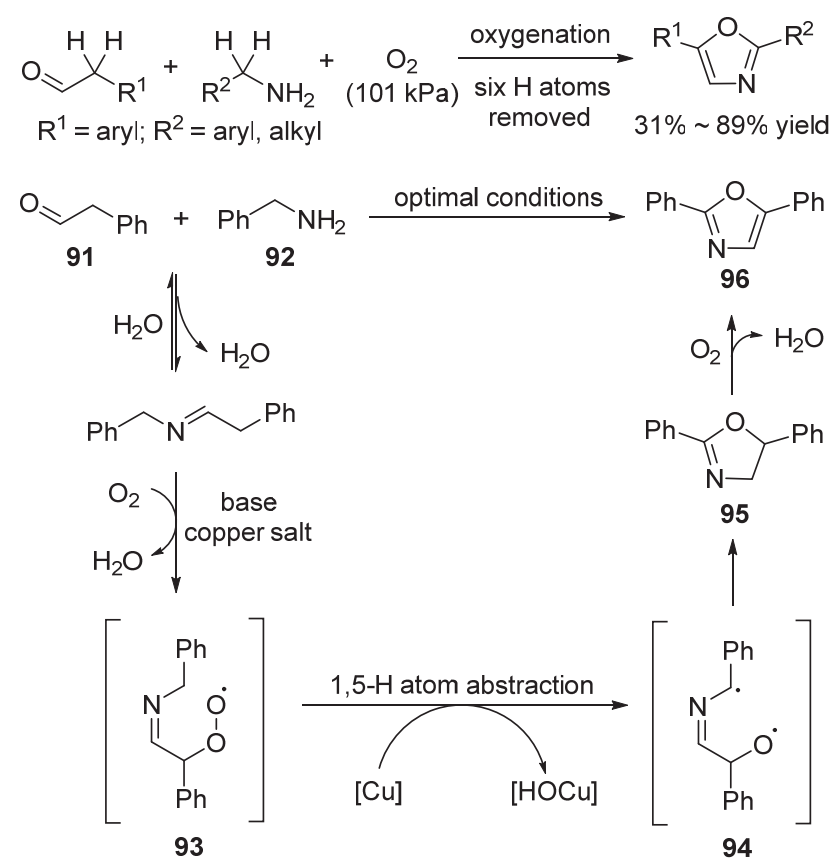

Scheme 41 Synthesis of oxazoles through a $\mathrm{Cu}$-mediated aerobic oxidative dehydrogenative annulation

Recently an annulation of internal alkynes, amines and molecular oxygen for the construction of oxazole via copper catalysis was disclosed by the same group (Eq. 44). ${ }^{[88]}$ Subsequently, they also explored the use of the element sulfur in the cyclization with primary amines and aldehydes. The three-component reaction afforded thiazoles and the oxygen acted as an oxidant (Eq. 45). ${ }^{[89]}$

In 2011, a copper-catalyzed Ullmann-type coupling reaction of benzylamine and 2-halobenzamides was developed by Fu's group. The transformation produced quinazolinone derivatives under aerobic oxidative conditions

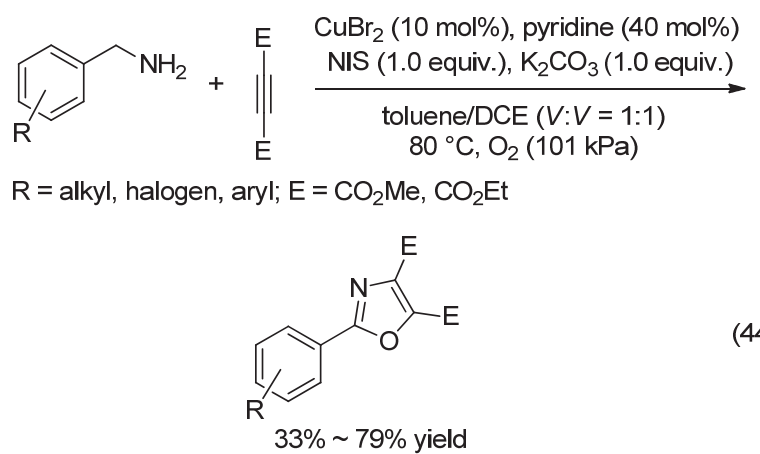

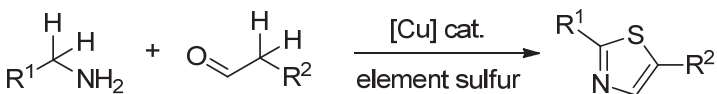

$$
\begin{aligned}
& \mathrm{R}^{1}=\text { aryl, alkyl; } \mathrm{R}^{2}=\text { aryl } \quad \mathrm{O}_{2} \quad 30 \% \sim 76 \% \text { yield }
\end{aligned}
$$

(Eq. 46) ${ }^{[90]}$ Four years later, a similar cyclization catalyzed by $\mathrm{CuO}$ nanoparticles was reported by Patel and coworkers (Eq. 47). ${ }^{[91]}$

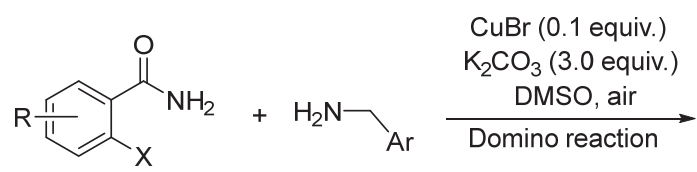

$\mathrm{X}=\mathrm{I}, \mathrm{Br}, \mathrm{Cl} ; \mathrm{R}=\mathrm{H}, \mathrm{Me}, \mathrm{OMe}, \mathrm{Cl}, \mathrm{NO}_{2}$

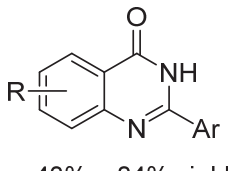

$43 \% \sim 84 \%$ yield

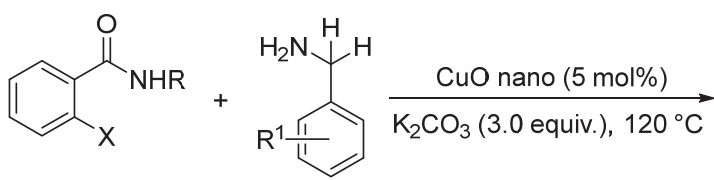

$\mathrm{X}=\mathrm{Br}, \mathrm{l} ; \mathrm{R}=\mathrm{H}$, alkyl, aryl;

$\mathrm{R}^{1}=\mathrm{H}, \mathrm{Me}, \mathrm{OMe}, \mathrm{Cl}, \mathrm{F}, \mathrm{NO}_{2}$<smiles>[R]c1ccc(-c2nc3ccccc3c(=O)n2[R])cc1</smiles>

$\mathrm{Ji}$ and coworkers ${ }^{[92]}$ demonstrated that the $\mathrm{CuI} / \mathrm{BF}_{3} \bullet \mathrm{Et}_{2} \mathrm{O}$ catalyst system promotes the cyclization of ketones and benzylamines to produce highly substituted imidazoles (Eq. 48)

Recently, the 1,2,4-trisubstituted-( $(1 H)$-imidazoles synthesis through $\mathrm{Cu}(\mathrm{OTf})_{2}$ or $\mathrm{I}_{2}$-catalyzed $\mathrm{C}-\mathrm{C}$ bond cleavage of chalcones and cyclization with benzylamines was developed by Somappa's group (Eq. 49). ${ }^{[93]}$

A simple solvent-free and catalyst-free synthesis of benzazoles from alkylamines and $o$-hydroxy/amino/mercaptan anilines has been developed by Nguyen's group. ${ }^{[94]}$ 

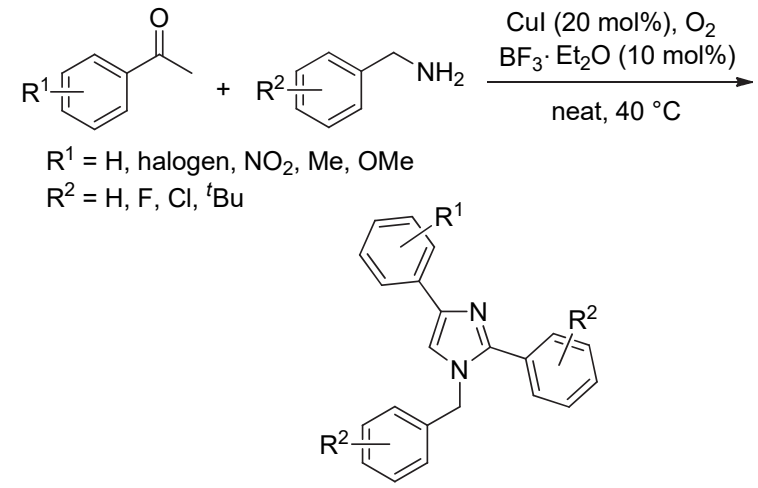

$39 \% \sim 76 \%$ yield

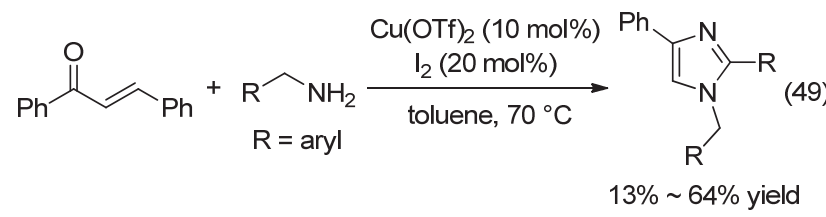

In the reaction, sulfur played the role of a traceless oxidizing agent (Eq. 50). A similar synthesis of benzimidazoles through organocatalytic coupling of benzylamines and 1,2diaminobenzene was subsequently reported (Scheme 42). The authors ${ }^{[95]}$ also presented the transformation of primaryamines into imines by the use of electron-rich salicylic acids catalysts under an oxygen atmosphere.
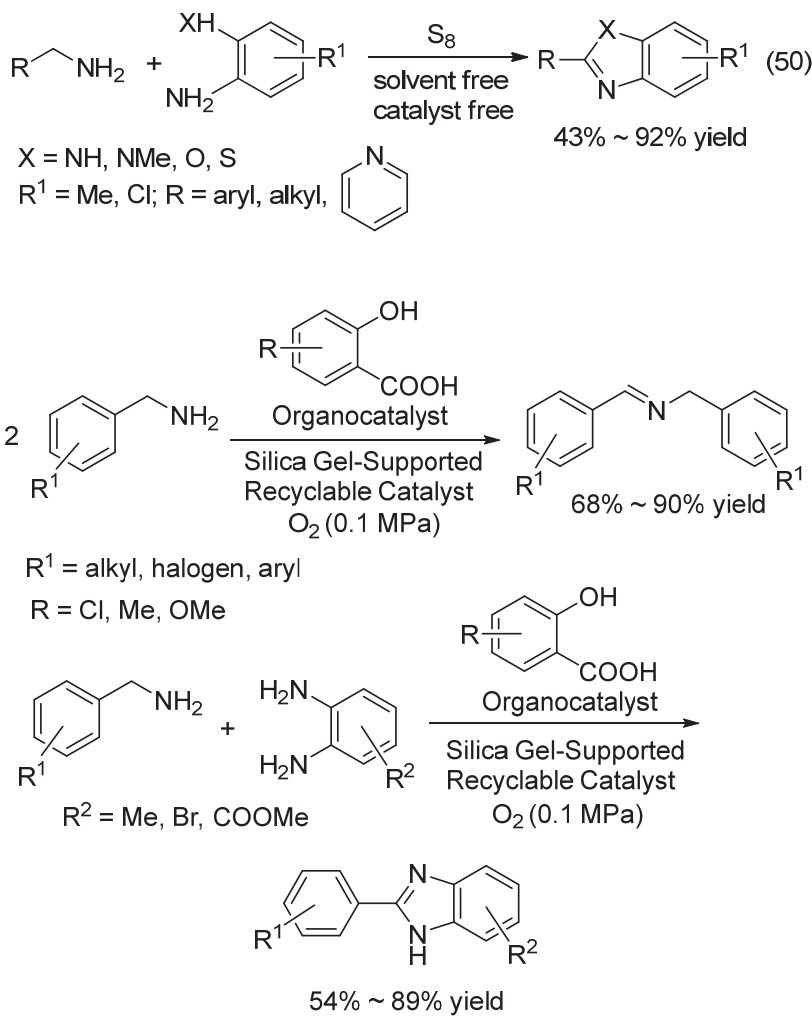

Scheme 42 Synthesis of benzimidazole and $N$-benzylidenebenzylamines

Gopalaiah and coworkers ${ }^{[96]}$ developed an ironcatalyzed aerobic oxidative cyclization reaction of 2-ami- nobenzyl alcohols with benzylamines leading to 2-substituted quinazolines. They found that chlorobenzene was the optimal solvent after investigation of reaction conditions (Eq. 51).

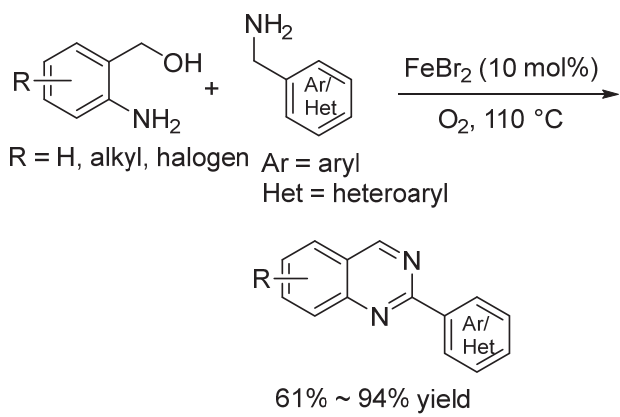

\subsection{Miscellaneous roles}

Sodium azide is an important nitrogen source in organic synthesis. A three-component reaction of sodium azide, primary amines and 2-bromobenzaldehydes for the synthesis of $2 \mathrm{H}$-indazoles has been reported by Lee and coworkers $^{[97]}$ (Eq. 52). The reaction was performed in the absence of oxidant. A similar strategy for quinazoline synthesis by the use of sodium azide, primary amines and 2-bromobenzaldehydes was subsequently disclosed by Wu's group. ${ }^{[98]}$ Base on their results, they mentioned that oxygen from air acted as oxidant in their transformation (Eq. 53).

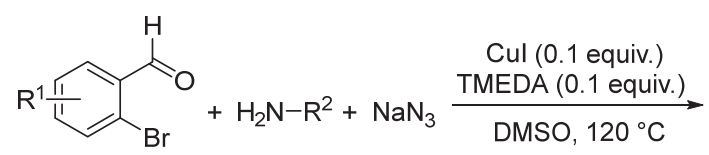

$\mathrm{R}^{1}=\mathrm{H}, 5-\mathrm{F}, 4,5-\mathrm{OCH}_{2} \mathrm{O}, 4-\mathrm{Me}$

$\mathrm{R}^{2}=$ aryl, alkyl

$$
\text { 30\% 96\% yield }
$$
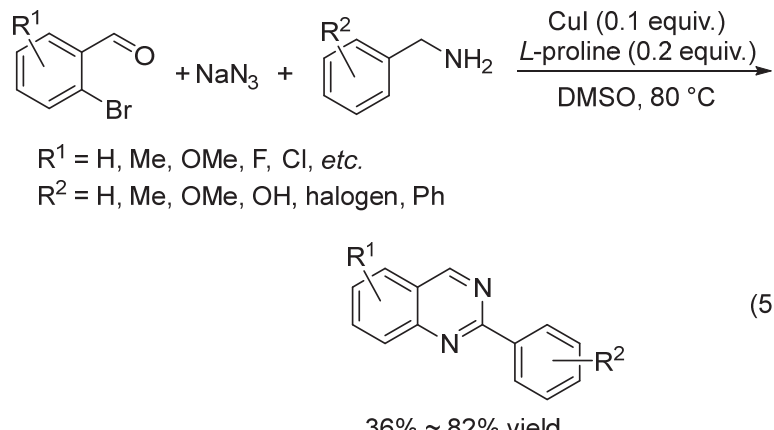

In the presence of elemental sulfur, a deaminative cross coupling reaction of two different primary amines leading to various thioamides has been achieved by Nguyen's group $^{[99]}$ (Eq. 54).

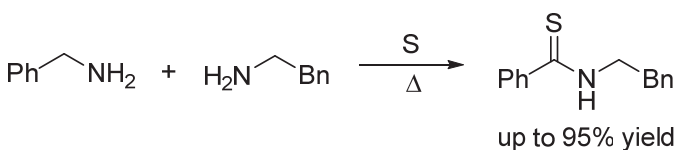


The deamination of benzylamines to realize functionalization of benzylic carbon is also a novel usage in oxidative coupling reactions. Satyanarayana and coworkers ${ }^{[100]} \mathrm{de}-$ veloped an interesting Pd-catalyzed deamination and cyclization of benzylamine with iodoarenes. Benzylamine provided three reaction sites, a benzylic $\mathrm{C}-\mathrm{H}$ and two aromatic $\mathrm{C}-\mathrm{H}$ bonds, giving the fused tricyclic fluorenones (Scheme 43).

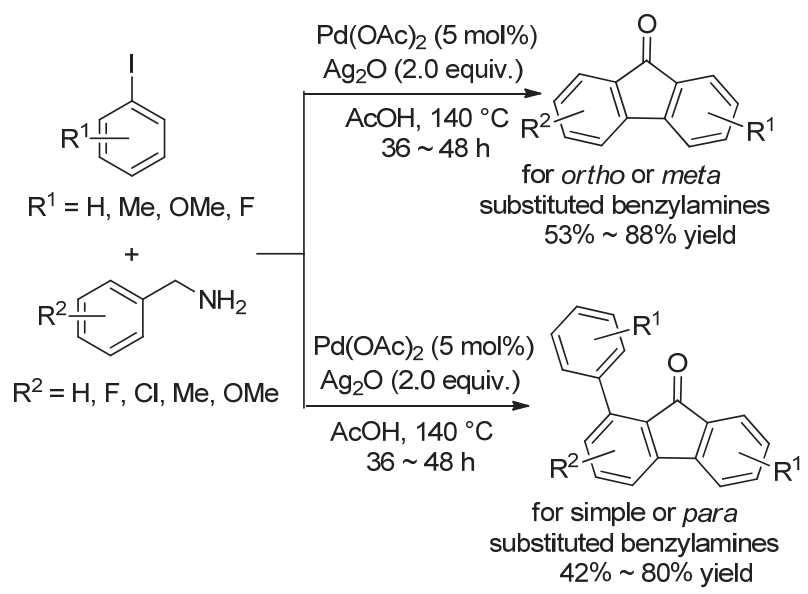

Scheme 43 Pd-catalyzed deamination and cyclization of benzylamine with iodoarenes

The deamination and condsention of benzylamines with $N, N$-dimethylaniline derivatives produced 4,4'-diaminotriarylmethanes in the presence of 4,6-dihydroxysalicylic acid and $N$-iodosuccinimide (Scheme 44). ${ }^{[101]}$

In 2014, our group ${ }^{[102]}$ developed an oxidative olefination reaction between aliphatic primary amines and 2-methyl azaheteroarenes using $N$-bromosuccinimide as catalyst and tert-butyl hydroperoxide as oxidant. This method achieved the complete $(E)$-configuration selectivity in the construction of 2-styrylquinolines (Eq. 55).

Recently, by the use of deamination of benzylamines, Bharate and coworkers ${ }^{[103]}$ reported a similar olefination under ionic liquid mediated conditions. Moreover, the benzoylation of $a z a$-heterocycles was also presented in this work (Scheme 45). The benzoylation of esters to bis-acyl ketals via oxidative deamination of benzylamine has been recently presented (Eq. 56). ${ }^{[104]}$

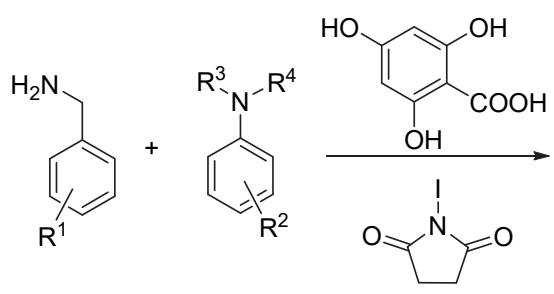

$\mathrm{R}^{1}=\mathrm{H}, \mathrm{Me}, \mathrm{OMe},{ }^{t} \mathrm{Bu}, \mathrm{Cl}, \mathrm{CF}_{3}, \mathrm{Ph}$, etc. $\mathrm{R}^{2}=\mathrm{H}, \mathrm{Me}, \mathrm{Cl}, \mathrm{OMe} ; \mathrm{R}^{3}, \mathrm{R}^{4}=\mathrm{H}, \mathrm{Me}, \mathrm{Et}, \mathrm{Ph}$<smiles></smiles>

Scheme 44 Deamination and condsention of benzylamines with $\mathrm{N}, \mathrm{N}$-dimethylaniline derivatives

$$
\begin{aligned}
& \underset{\mathrm{N}}{\mathrm{Ar}}+\mathrm{CH}_{3}{ }_{\mathrm{H}_{2} \mathrm{~N}} \widehat{\mathrm{R}}_{\mathrm{R}} \frac{\mathrm{NBS}(0.2 \text { equiv. })}{\operatorname{TBHP}(2.0 \text { equiv. })} \\
& \mathrm{R}=\text { aryl, alkyl }
\end{aligned}
$$

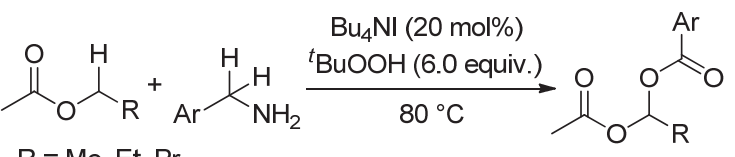

$$
\begin{aligned}
& \mathrm{R}=\mathrm{Me}, \mathrm{Et}, \mathrm{Pr} \\
& 52 \% \sim 80 \% \text { yield }
\end{aligned}
$$

Indole-3-carboxylates could be constructed by deamination/cyclization of tert-butyl-2-(2-aminophenyl)acetate and benzylamine under the $o$-naphthoquinone-catalyzed aerobic oxidation conditions (Eq. 57). ${ }^{[105]}$

A ligand-promoted ruthenium-catalyzed dehydrogenative and deaminative coupling reaction of 2-aminophenyl ketones and 2-aminobenzamides with amines was recently disclosed by Yi's group ${ }^{[106]}$ (Scheme 46).

\section{Conclusion}

In this review, the utilization of $N$-alkylamines in oxida-

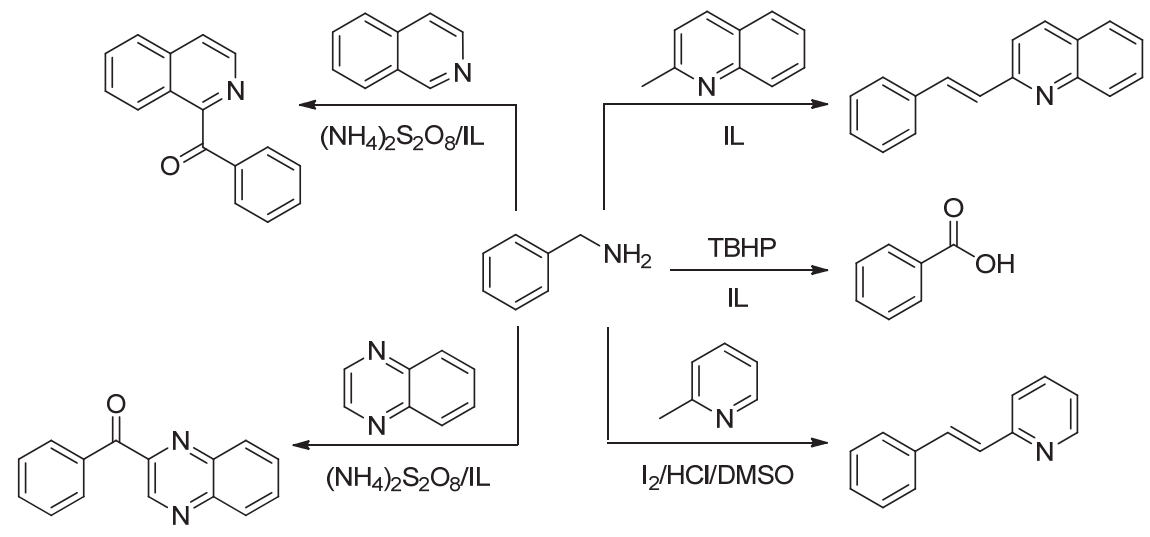

Scheme 45 Deamination and coupling reaction of benzylamine 


$$
\begin{aligned}
& \mathrm{R}^{1}=\mathrm{H}, \text { halogen, } \mathrm{OMe}, \mathrm{Ph} \\
& \mathrm{R}^{2}=\mathrm{H}, \mathrm{Ph}, \mathrm{Me}, \mathrm{OMe} \text {, halogen, etc. }
\end{aligned}
$$<smiles>[R]c1ccc(-c2[nH]c3cc[R11]cc3c2C(=O)OCC)cc1</smiles>

$20 \% \sim 72 \%$ yield<smiles>O=C1C=C(c2ccccc2)c2ccccc2C1=O</smiles><smiles>[R]NC(=O)c1ccccc1N</smiles><smiles>[R]c1nc2ccccc2c(=O)n1[R]</smiles><smiles>[R]CNCC(C)CCc1cccc(N)c1C([R])=O</smiles>

[Ru] $46 \% \sim 88 \%$ yield $\mathrm{R}^{1}, \mathrm{R}^{2}=$ aryl, alkyl<smiles>[R]c1nc([R])c2ccccc2n1</smiles><smiles>CC(C)(C)c1ccc(O)c(O)c1</smiles>

L

Scheme 46 Deamination and cyclization of benzylamines

tive coupling reactions is summarized. These $N$-alkylamines are easily available and easy to handle. These properties make them versatile synthetic building blocks in oxidative coupling reactions. They can offer different products through providing their $\alpha$-carbon and (or) nitrogen moieties, and a variety of efficient $\mathrm{C}-\mathrm{C}$ and $\mathrm{C}$-heteroatom bond-forming reactions can be catalyzed starting from them. Based on the published examples, we think that the future research of $N$-alkylamines will focus on the development of asymmetric transformation, radical initiators and natural products synthesis.

\section{References}

[1] (a) Murahashi, S.-I.; Zhang, D. Chem. Soc. Rev. 2008, 37, 1490.

(b) Li, C. J. Acc. Chem. Res. 2009, 42, 335.

(c) Scheuermann, C. J. Chem.-Asian J. 2010, 5, 436.

(d) Cho, S. H.; Kim, J. Y.; Kwak, J.; Chang, S. Chem. Soc. Rev. 2011, 40, 5068 .

(e) Yeung, C. S.; Dong, V. M. Chem. Rev. 2011, 111, 1215.

(f) Jones, K. M.; Klussmann, M. Synlett 2012, 23, 159.

(g) Girard, S. A.; Knauber, T.; Li, C. J. Angew. Chem., Int. Ed. 2014, 53, 74 . (h) Le Bras, J.; Muzart, J. Chem. Rev. 2011, 111, 1170.

[2] Li, Y.; Ma, L.; Li, Z. Chin. J. Org. Chem. 2013, 33, 704 (in Chinese). (李远明, 马丽娜, 李志平, 有机化学, 2013, 33, 704.)

[3] Edwards, P. M.; Schafer, L. L. Chem. Commun. 2018, 54, 12543.

[4] Ouyang, K.; Hao, W.; Zhang, W. X.; Xi, Z. Chem. Rev. 2015, 115, 12045

[5] Li, Z.; Li, C.-J. J. Am. Chem. Soc. 2005, 127, 3672.

[6] Tsang, A. S. K.; Todd, M. H. Tetrahedron Lett. 2009, 50, 1199.

[7] Shu, X. Z.; Xia, X. F.; Yang, Y. F.; Ji, K. G.; Liu, X. Y.; Liang, Y. M. J. Org. Chem. 2009, 74, 7464.

[8] Chu, L.; Qing, F.-L. Chem. Commun. 2010, 46, 6285.

[9] Boess, E.; Sureshkumar, D.; Sud, A.; Wirtz, C.; Farès, C.; Klussmann, M. J. Am. Chem. Soc. 2011, 133, 8106.

[10] Jones, K. M.; Karier, P.; Klussmann, M. ChemCatChem 2012, 4 , 51.

[11] Huang, W.; Ni, C.; Zhao, Y.; Hu, J. New J. Chem. 2013, 37, 1684.

[12] Ho, H. E.; Ishikawa, Y.; Asao, N.; Yamamoto, Y.; Jin, T. Chem. Commun. 2015, 51, 12764.

[13] Kim, Y. H.; Gil, M. G.; Kim, D. Y. Bull. Korean Chem. Soc. 2017 $38,1499$.

[14] Oss, G.; de Vos, S. D.; Luc, K. N. H.; Harper, J. B.; Nguyen, T. V. J. Org. Chem. 2018, 83, 1000.

[15] Gil-Negrete, J. M.; Pérez Sestelo, J.; Sarandeses, L. A. J. Org. Chem. 2019, 84, 9778.

[16] Patil, M. R.; Dedhia, N. P.; Kapdi, A. R.; Kumar, A. V. J. Org. Chem. 2018, 83, 4477.

[17] Xu, C.; Zhu, Z.; Wang, Y.; Jing, Z.; Gao, B.; Zhao, L.; Dong, W. K. J. Org. Chem. 2019, 84, 2234.

[18] Yang, Q.; Zhang, L.; Ye, C.; Luo, S.; Wu, L. Z.; Tung, C. H. Angew. Chem., Int. Ed. 2017, 56, 3694.

[19] Nishino, M.; Hirano, K.; Satoh, T.; Miura, M. J. Org. Chem. 2011, $76,6447$.

[20] Zhao, M.-N.; Yu, L.; Hui, R.-R.; Ren, Z.-H.; Wang, Y.-Y.; Guan, Z.-H. ACS Catal. 2016, 6, 3473.

[21] Ma, Y.; Zhang, G.; Zhang, J.; Yang, D.; Wang, R. Org. Lett. 2014, $16,5358$.

[22] Li, Z.; Li, C.-J. Org. Lett. 2004, 6, 4997.

[23] Niu, M.; Yin, Z.; Fu, H.; Jiang, Y.; Zhao, Y. J. Org. Chem. 2008, 73, 3961.

[24] Jin, X.; Yamaguchi, K.; Mizuno, N. RSC Adv. 2014, 4, 34712.

[25] Sun, S.; Li, C.; Floreancig, P. E.; Lou, H.; Liu, L. Org Lett. 2015, $17,1684$.

[26] Huang, T.; Liu, X.; Lang, J.; Xu, J.; Lin, L.; Feng, X. ACS Catal. 2017, 7, 5654

[27] Ma, L.; Shi, X.; Li, X.; Shi, D. Org. Chem. Front. 2018, 5, 3515.

[28] Li, Z.; Li, C.-J. J. Am. Chem. Soc. 2005, 127, 6968.

[29] Baslé, O.; Li, C.-J. Org. Lett. 2008, 10, 3661.

[30] Huang, L.; Niu, T.; Wu, J.; Zhang, Y. J. Org. Chem. 2011, 76, 1759.

[31] Ratnikov, M. O.; Xu, X.; Doyle, M. P. J. Am. Chem. Soc. 2013, 135, 9475.

[32] Singh, A.; Arora, A.; Weaver, J. D. Org. Lett. 2013, 15, 5390.

[33] Dhineshkumar, J.; Lamani, M.; Alagiri, K.; Prabhu, K. R. Org. Lett. 2013, 15, 1092.

[34] Zhou, S.; Wang, J.; Lin, D.; Zhao, F.; Liu, H. J. Org. Chem. 2013 $78,11204$.

[35] Liu, X.; Zhang, J.; Ma, S.; Ma, Y.; Wang, R. Chem. Commun. 2014, 50, 15714.

[36] Yu, C.; Patureau, F. W. Angew. Chem., Int. Ed. 2018, 57, 11807.

[37] Kibriya, G.; Bagdi, A. K.; Hajra, A. J. Org. Chem. 2018, 83, 10619.

[38] Girish, Y. R.; Jaiswal, K.; Prakash, P.; De, M. Catal. Sci. Technol. 2019, 9, 1201.

[39] Zhang, Y.; Fu, H.; Jiang, Y.; Zhao, Y. Org. Lett. 2007, 9, 3813.

[40] Li, L. T.; Li, H. Y.; Xing, L. J.; Wen, L. J.; Wang, P.; Wang, B. Org. Biomol. Chem. 2012, 10,9519.

[41] Singh, S. K.; Chandna, N.; Jain, N. Org. Lett. 2017, 19, 1322.

[42] Lao, Z.-Q.; Zhong, W.-H.; Lou, Q.-H.; Li, Z.-J.; Meng, X.-B. Org. Biomol. Chem. 2012, 10, 7869 . 
[43] Zhao, Y.; Zeng, J.; Xia, W. Chin. J. Org. Chem. 2020, 40, 133 (in Chinese).

(赵亚婷，曾俊杰，夏吾昫，有机化学, 2020, 40, 133.)

[44] Dhineshkumar, J.; Samaddar, P.; Prabhu, K. R. ACS Omega. 2017, 2, 4885 .

[45] Lin, B.; Shi, S.; Lin, R.; Cui, Y.; Fang, M.; Tang, G.; Zhao, Y. J. Org. Chem. 2018, 83, 6754.

[46] Li, H.; He, Z.; Guo, X.; Li, W.; Zhao, X.; Li, Z. Org. Lett. 2009, 11, 4176.

[47] Yoo, W.-J.; Tanoue, A.; Kobayashi, S. Chem.-Asian J. 2012, 7, 2764.

[48] Xing, L. J.; Wang, X. M.; Li, H. Y.; Zhou, W.; Kang, N.; Wang, P.; Wang, B. RSC Adv. 2014, 4, 26783.

[49] Xing, L. J.; Lu, T.; Fu, W. L.; Lou, M. M.; Chen, B.; Wang, Z. S.; Jin, Y.; Li, D.; Wang, B. Adv. Synth. Catal. 2015, 357, 3076.

[50] Guo, S.; Gong, J.; Lu, L.; Zhu, Z.; Cai, H. Chin. J. Org. Chem. 2015, 35, 1348 (in Chinese). (郭生梅, 龚久涵, 卢林, 朱正, 蔡琥, 有机化学, 2015, 35, 1348.)

[51] Zheng, Y.; Mao, J.; Chen, J.; Rong, G.; Liu, D.; Yan, H.; Chi, Y.; $\mathrm{Xu}, \mathrm{X} . R S C A d v . \mathbf{2 0 1 5}, 5,50113$.

[52] Volvoikar, P. S.; Tilve, S. G. Org. Lett. 2016, 18, 892.

[53] Wang, S.; Li, X.; Zang, J.; Liu, M.; Zhang, S.; Jiang, G.; Ji, F. J. Org. Chem. 2020, 85, 2672.

[54] Tian, J. S.; Loh, T. P. Angew. Chem., Int. Ed. 2010, 49, 8417.

[55] Chen, M.; Peng, J.; Mao, T.; Huang, J. Org. Lett. 2014, 16, 6286.

[56] Gogoi, A.; Guin, S.; Rout, S. K.; Patel, B. K. Org. Lett. 2013, 15, 1802.

[57] Paladugu, S.; Mainkar, P. S.; Chandrasekhar, S. ACS Omega 2018 , $3,4289$.

[58] Li, B.; Xu, H.; Wang, H.; Wang, B. ACS Catal. 2016, 6, 3856.

[59] Xue, D.; Long, Y. Q. J. Org. Chem. 2014, 79, 4727.

[60] Zhang, T. S.; Hao, W. J.; Wang, N. N.; Li, G.; Jiang, D. F.; Tu, S. J.; Jiang, B. Org. Lett. 2016, 18, 3078.

[61] Guerrero, I.; San Segundo, M.; Correa, A. Chem. Commun. 2018, $54,1627$.

[62] Constantin, T.; Zanini, M.; Regni, A.; Sheikh, N. S.; Julia, F.; Leonori, D. Science 2020, 367, 1021.

[63] Xiao, T.; Li, L.; Lin, G.; Mao, Z. W.; Zhou, L. Org Lett. 2014, 16, 4232 .

[64] Wang, N.-N.; Hao, W.-J.; Zhang, T.-S.; Li, G.; Wu, Y.-N.; Tu, S.-J.; Jiang, B. Chem. Commun. 2016, 52, 5144.

[65] Zhang, T. S.; Zhao, Q.; Hao, W. J.; Tu, S. J.; Jiang, B. Chem.-Asian J. 2019, 14, 1042.

[66] Wu, X.; Chen, D.-F.; Chen, S.-S.; Zhu, Y.-F. Eur. J. Org. Chem. 2015, 2015, 468.

[67] Li, Z. L.; Sun, K. K.; Wu, P. Y.; Cai, C. J. Org. Chem. 2019, 84, 6830.

[68] Monguchi, D.; Fujiwara, T.; Furukawa, H.; Mori, A. Org. Lett. 2009, 11, 1607.

[69] Daggupati, R. V.; Malapaka, C. Org. Chem. Front. 2018, 5, 788.

[70] Ranjith, J.; Krishna, P. R. Tetrahedron Lett. 2019, 60, 1437.

[71] Wu, W.; Su, W. J. Am. Chem. Soc. 2011, 133, 11924.

[72] Li, L. T.; Huang, J.; Li, H. Y.; Wen, L. J.; Wang, P.; Wang, B. Chem. Commun. 2012, 48, 5187.

[73] Wang, Z.; Zhang, L.; Zhang, F.; Wang, B. Chin. J. Org. Chem. 2019, 39, 2323 (in Chinese).

(王震，张玲，张富庚，王彬，有机化学, 2019, 39, 2323.)
[74] Sonobe, T.; Oisaki, K.; Kanai, M. Chem. Sci. 2012, 3, 3249.

[75] Wan, C.; Zhang, J.; Wang, S.; Fan, J.; Wang, Z. Org. Lett. 2010, 12, 2338.

[76] Yang, S.; Yang, Y.; Li, F.; Liu, X. Tetrahedron Lett. 2020, 61, 151846.

[77] Jiang, H.; Huang, H.; Cao, H.; Qi, C. Org. Lett. 2010, 12, 5561.

[78] Chen, Z.; Li, H.; Dong, W.; Miao, M.; Ren, H. Org. Lett. 2016, 18, 1334.

[79] Zhang, X.; He, Y.; Li, J.; Wang, R.; Gu, L.; Li, G. J. Org. Chem. 2019, 84, 8225.

[80] Yan, Y.; Zhang, Y.; Zha, Z.; Wang, Z. Org. Lett. 2013, 15, 2274.

[81] Chandra Mohan, D.; Nageswara Rao, S.; Ravi, C.; Adimurthy, S. Org. Biomol. Chem. 2015, 13, 5602.

[82] Qian, P.; Yan, Z.; Zhou, Z.; Hu, K.; Wang, J.; Li, Z.; Zha, Z.; Wang, Z. Org. Lett. 2018, 20, 6359.

[83] Qian, P.; Yan, Z.; Zhou, Z.; Hu, K.; Wang, J.; Li, Z.; Zha, Z.; Wang, Z. J. Org. Chem. 2019, 84, 3148.

[84] Li, M.; Xie, Y.; Ye, Y.; Zou, Y.; Jiang, H.; Zeng, W. Org. Lett. 2014 16,6232 .

[85] Wang, H.; Xu, W.; Wang, Z.; Yu, L.; Xu, K. J. Org. Chem. 2015, $80,2431$.

[86] (a) Tan, Z.; Zhao, H.; Zhou, C.; Jiang, H.; Zhang, M. J. Org. Chem. 2016, $81,9939$.

(b) Li, Z.; Wu, S.-S.; Luo, Z.-G.; Liu, W.-K.; Feng, C.-T.; Ma, S.-T J. Org. Chem. 2016, 81, 4386.

[87] Xu, Z.; Zhang, C.; Jiao, N. Angew. Chem., Int. Ed. 2012, 51, 11367.

[88] Pan, J.; Li, X.; Qiu, X.; Luo, X.; Jiao, N. Org. Lett. 2018, 20, 2762.

[89] Wang, X.; Qiu, X.; Wei, J.; Liu, J.; Song, S.; Wang, W.; Jiao, N. Org. Lett. 2018, 20, 2632.

[90] Xu, W.; Jin, Y.; Liu, H.; Jiang, Y.; Fu, H. Org. Lett. 2011, 13, 1274.

[91] Modi, A.; Ali, W.; Mohanta, P. R.; Khatun, N.; Patel, B. K. ACS Sustainable Chem. Eng. 2015, 3, 2582.

[92] Cai, Z.-J.; Wang, S.-Y.; Ji, S.-J. Org. Lett. 2012, 14, 6068.

[93] Salfeena, C. T. F.; Jalaja, R.; Davis, R.; Suresh, E.; Somappa, S. B. ACS Omega 2018, 3, 8074 .

[94] Nguyen, T. B.; Ermolenko, L.; Dean, W. A.; Al-Mourabit, A. Org. Lett. 2012, 14, 5948.

[95] Dong, C. P.; Higashiura, Y.; Marui, K.; Kumazawa, S.; Nomoto, A.; Ueshima, M.; Ogawa, A. ACS Omega. 2016, 1, 799.

[96] Gopalaiah, K.; Saini, A.; Devi, A. Org. Biomol. Chem. 2017, 15, 5781.

[97] Kumar, M. R.; Park, A.; Park, N.; Lee, S. Org. Lett. 2011, 13, 3542.

[98] Xu, C.; Jia, F.-C.; Zhou, Z.-W.; Zheng, S.-J.; Li, H.; Wu, A.-X. J. Org. Chem. 2016, $81,3000$.

[99] Nguyen, T. B.; Ermolenko, L.; Al-Mourabit, A. Org. Lett. 2012, 14, 4274.

[100] Ravi Kumar, D.; Satyanarayana, G. Org. Lett. 2015, 17, 5894.

[101] Dong, C.-P.; Kodama, S.; Uematsu, A.; Nomoto, A.; Ueshima, M.; Ogawa, A. J. Org. Chem. 2017, 82, 12530.

[102] Gong, L.; Xing, L. J.; Xu, T.; Zhu, X. P.; Zhou, W.; Kang, N.; Wang, B. Org. Biomol. Chem. 2014, 12, 6557.

[103] Sharma, R.; Abdullaha, M.; Bharate, S. B. J. Org. Chem. 2017, 82, 9786.

[104] Majji, G.; Rajamanickam, S.; Khatun, N.; Santra, S. K.; Patel, B. K. J. Org. Chem. 2015, 80, 3440.

[105] Kim, K.; Kim, H. Y.; Oh, K. Org. Lett. 2019, $21,6731$.

[106] Kirinde Arachchige, P. T.; Yi, C. S. Org. Lett. 2019, 21, 3337.

(Cheng, F.) 